Nicolás Mariné

\title{
La American Society of Landscape Architects y la difícil definición del paisajista moderno
}

\author{
Keywords: : Landscape architecture, Frederick Law Olmsted, Frederick Law Olmsted Jr., Ameri- \\ can Society of Landscape Architects
}

In current times, several landscape theorists have noticed a persistent crisis in the professional identity of landscape architecture. Actually, this problem has a long history that can be traced back to when Frederick Law Olmsted, one of the creators of New York's Central Park, conceived the profession. Following some of the ideas that recent publications have hinted at, in this paper we look into the difficulties that the American Society of Landscape Architects (ASLA), the first official organization of its kind, went through during the early attempts to define landscape architecture as a modern profession.

To do this, we have consulted the original documents that the ASLA produced between its foundation and the middle of the 20th century. These are currently stored in the Library of Congress of the United States and some of them remain unpublished up until now. A critical reading of these records highlights the conflicts and complications in defining the field of landscape architecture and building a specific public profile.

\section{Introducción}

Durante la última década, han sido varios los académicos y profesionales que se han cuestionado el contenido esencial de la arquitectura del paisaje. En el prefacio al volumen recopilatorio de sus escritos, James Corner (2014) se lamenta del escaso avance de la profesión en el campo intelectual. Compara la situación actual con la que, años atrás, le llevó a tratar de establecer un corpus teórico unificado que equiparase el paisajismo a otras profesiones como la arquitectura, el urbanismo o la ecología. Por su parte, Charles Waldheim, al detectar un problema similar, llama la atención sobre la necesidad de acometer "los asuntos fundamentales sobre la identidad profesional y disciplinar del campo [de la arquitectura del paisaje]". (2014:187)

El planteamiento de Waldheim no es una novedad: las miradas críticas a esta falta de identidad profesional de la arquitectura del paisaje vienen de más atrás. Hace casi treinta años se nos avisaba ya de que los "arquitectos del paisaje se enfrentan a una crisis de identidad continua" (Nasar y Johnson 1990: 102). Anne Whiston Spirn observaba a este respecto que "las tensiones y contradicciones en la arquitectura del paisaje [...] se originan en conflictos, inherentes y no resueltos, entre las disciplinas de las que se nutre" (1997: 254). Es decir, el trabajo del arquitecto del paisaje combina las tareas de un conjunto de profesiones (agricultura, arquitectura, ur- banismo, ingeniería, etc.) que no siempre son fáciles de articular en una disciplina única (Jellicoe 1961). Este problema se arrastra desde la concepción misma de la profesión por el que es ampliamente aceptado como su creador, Frederick Law Olmsted:

Quizás haya un tipo de crisis de identidad enraizada en la diversidad de la profesión. Probablemente, el modelo de tal diversidad (y sus consiguientes problemas de comunicación) lo estableció en el siglo XIX Frederick Law Olmsted, el cual se implicó en un amplio abanico de tareas desde el paisajismo de pequeñas viviendas a parques, sistemas de parques y la protección de la naturaleza. (Nadenicek y Hastings 2000: 133)

Es decir, al ser una amalgama de diversas tareas, la profesión estaba en cierta manera destinada al conflicto. De hecho, antes de Olmsted, el diseño de jardines y parques (ya fuera aislado o en conjunción con infraestructuras o áreas urbanas) había sido tarea de arquitectos, ingenieros, jardineros o pintores, y, muchas veces, de varios de ellos en grupo. Pero nunca antes de la segunda mitad del siglo XIX se había planteado una profesión que pretendiera cubrir todas las disciplinas de manera simultánea.

Por ello, la literatura reciente se ha centrado en la formación del paisajista durante el siglo XX procurando dotarle de lógica (Baird y Szczygiel 2006; Brown y Corry 2011). De es- 


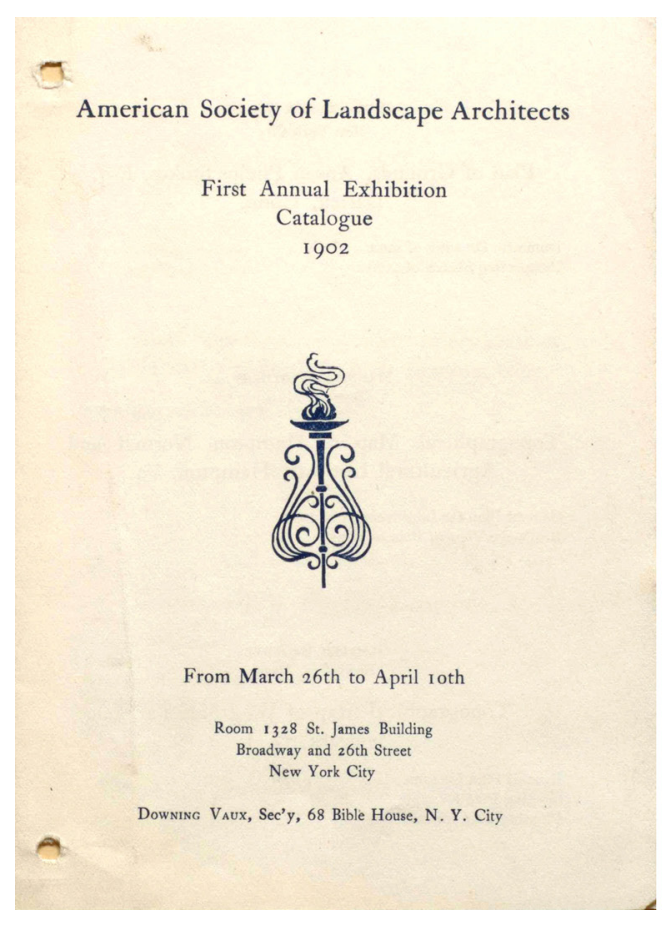

tas contribuciones se desprende que la indefinición profesional podría deberse en parte a los problemas que tuvo para resolver esta cuestión la primera asociación que formaron los arquitectos del paisaje: la American Society of Landscape Architects (ASLA). Sin embargo, esta es una vía en la que la literatura especializada no ha profundizado mucho, y menos aún fuera de lo anglosajón. Por lo tanto, se plantea en este artículo una revisión de los trabajos de dicha sociedad durante las primeras décadas de su existencia.

En general, los textos que trata la ASLA han tenido enfoques históricos y no han considerado tanto su papel dentro de la crisis profesional que sufre el paisajismo (Newton 1971; Simo 1999). Por ello, se recurre aquí a los documentos originales de la asociación que, en su gran mayoría, nunca han sido publicados. Se han consultado los fondos históricos de la sociedad archivados en la Biblioteca del Congreso de Estados Unidos, que abarcan desde su fundación hasta la década de $1960^{1}$. Puesto que la gran mayoria del material con el que se ha trabajado es inédita, un recurso de gran interés y de difícil acceso, se ha decidido optar por citas más largas que iluminen mejor el contenido de los documentos y el tema tratado.

\section{La American Society of Landscape Architects}

Alrededor de 1895, William H. Manning, antiguo empleado de la firma de Olmsted,

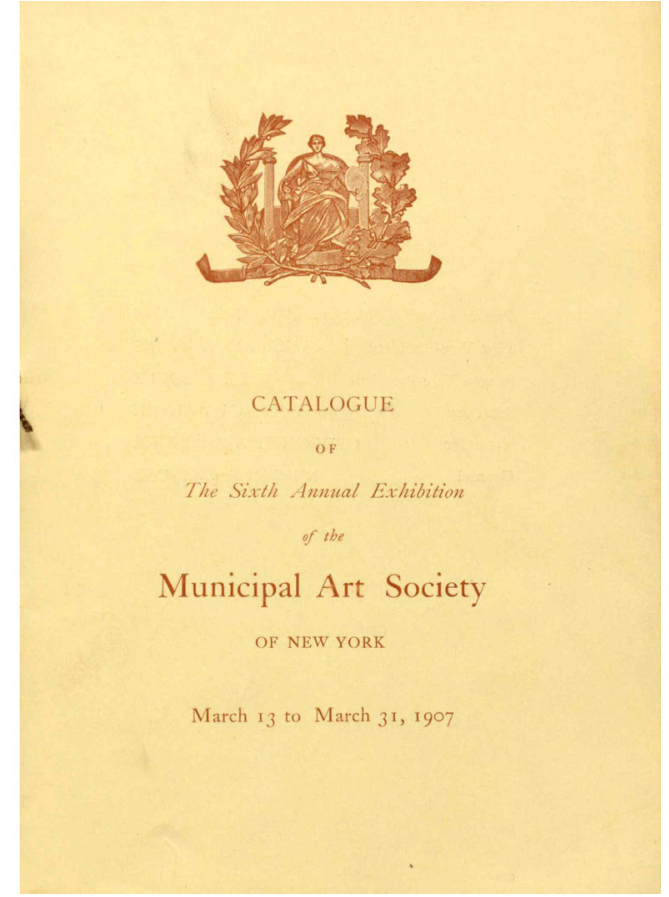

Figura 1. Primeras exposiciones que realizaron o en las que participaron los miembros de la ASLA. envió una carta a varias personas vinculadas con el diseño del paisaje, la jardinería, la arquitectura y la conservación de espacios naturales. En ella, pedía opinión sobre si convenía formar una asociación de "aquellos que abordan la profesión dentro de un marco estrictamente laboral" (VVAA 1895: 8). El gesto dio sus frutos y el 4 de enero de 1899, doce personas de distintos ámbitos se reunieron en Nueva York "con el propósito de organizar la American Society of Landscape Architects" (ASLA 1912: 17.)

Poco después de ser inaugurada, la sociedad se dedicó a difundir las bondades de la arquitectura del paisaje mediante diferentes exposiciones (figura 1) y no tardó en aprobar su Constitución con los objetivos principales de "promover el compañerismo entre sus miembros e incrementar la eficiencia de la profesión" (ASLA 1912: 10). Se trataba de cumplir así un deseo que ya había expresado el mismo Olmsted un tiempo atrás: "Lo que principalmente limita el éxito de nuestra profesión es el hecho de que muy pocos saben que la arquitectura del paisaje es un asunto en el que el asesoramiento profesional es muy deseable"; algo que solo se podría solucionar "a medida que la arquitectura del paisaje se vaya reconociendo como una profesión normalizada”. (Olmsted [1886] 1921: 189)

Por tanto, la sociedad no fue una plataforma de debate sobre cuestiones de estilo o método de proyecto. Su cometido principal fue el de concretar el ámbito profesional del 
Figura 2. Foto más antigua del conjunto de la ASLA que conserva la Biblioteca del Congreso.

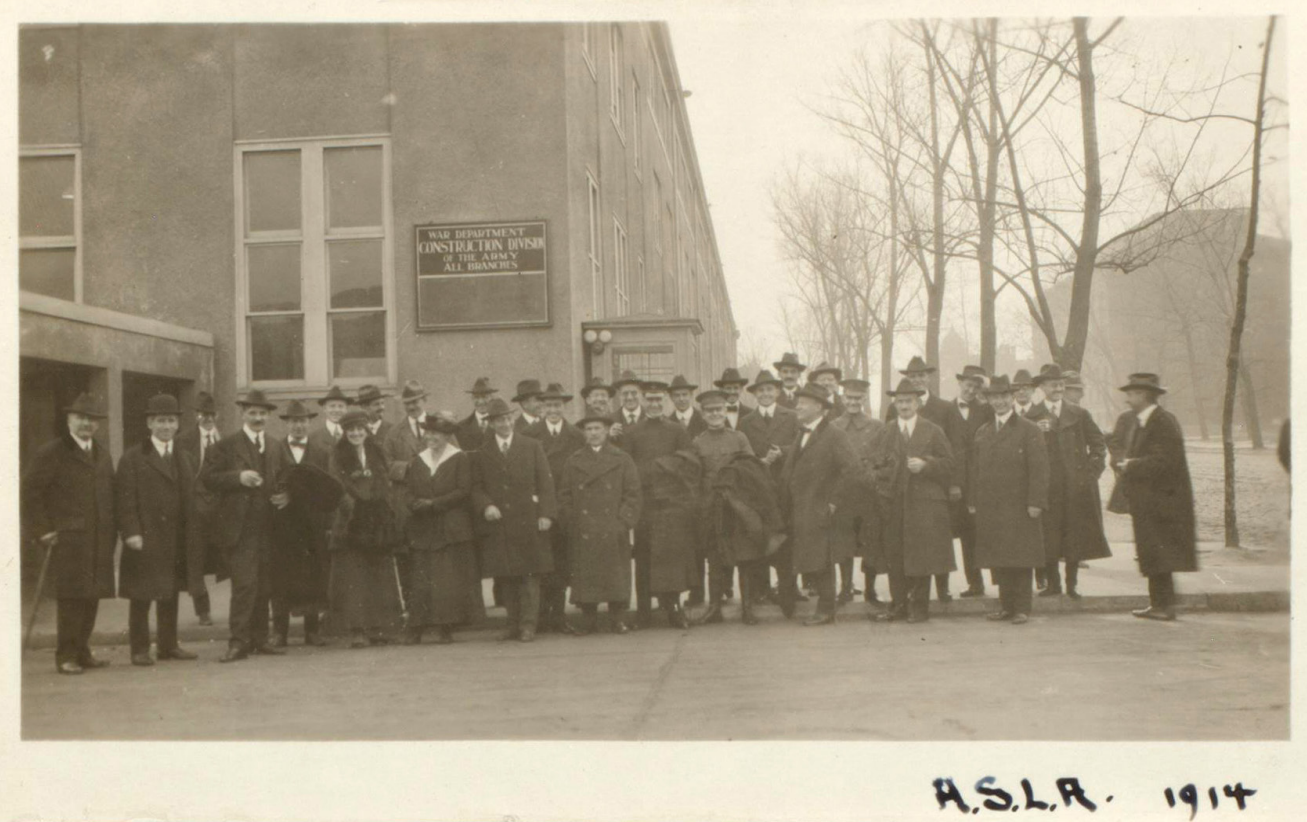

arquitecto del paisaje y proporcionar al público en general una idea clara del mismo. Sin embargo, uno de los rasgos característicos de la ASLA fue precisamente aquel que Olmsted había utilizado en varias ocasiones para definirse a sí mismo: la impracticidad ${ }^{2}$. (Olmsted 1882)

En el vocabulario de Olmsted, "práctico" era un insulto. El hombre práctico era el hombre conveniente, en el peor sentido de la palabra. El hombre practico elegía la más rápida y fácil solución a cualquier problema, sin referencia a la excelencia. (Sutton 1971: 7)

Frente a la vía rápida, Olmsted fue partidario del debate que permitiese obtener resultados más propios de un arte que de una profesión, independientemente del tiempo que ello llevase o de la ganancia que permitiera la respuesta inmediata. Greenleaf, uno de los presidentes de la sociedad, expresó este espíritu en un consejo a los paisajistas de la asociación:

No tengáis miedo de ser un poco visionarios. No aplaquéis la chispa de lo divino que lleváis dentro. Mantener la Arquitectura del Paisaje como un arte depende de nosotros; somos sus custodios. Que ninguno de nosotros, sea cual sea la tentación por la ganancia inmediata, venda lo que es su derecho natural por un plato de lentejas ${ }^{3}$. (Greenleaf 1924)

De esta forma, desde los comienzos de la ASLA, la impracticidad fue la característica principal. A pesar de que los miembros coincidieran en el deseo general de favorecer el estatus de la arquitectura del paisaje, lo cierto es que la discusión y el debate continuado fueron la norma. Es por ello que, por ejemplo, tardaron más de veinte años en concretar un código ético (Vernon 1987) y modificaron su reglamento tantas veces que se tuvo que reconocer que "la cuestión de la revisión de los estatutos de la sociedad es uno de esos problemas continuos que al parecer siempre nos ha de acompañar". (Pond 1931)

\section{Los herederos de Olmsted}

A principios del siglo XX Olmsted se encontraba en un estado mental muy deteriorado y moriría poco después. Pese a ello, su influencia en la sociedad fue evidente. Aparte del propio Manning, instruido en su estudio, también estuvo allí Downing Vaux, nieto de Andrew Jackson Downing (mentor de Olmsted) e hijo de Calbert Vaux, diseñador de Central Park junto a Olmsted y su socio durante varios años. Pero no solo eso, su hijastro John Charles Olmsted ${ }^{4}$ fue miembro fundador y su hijo Frederick Law Olmsted Jr. entró en la sociedad al año siguiente. De hecho, durante los primeros veinte años de existencia de la asociación, dos tercios de los presidentes que tuvo fueron empleados del estudio de Olmsted o del de Vaux. Olmsted no estuvo físicamente en la sociedad, pero si los discipulos que habian heredado sus ideas (figura 2).

Esta influencia de Olmsted no es una ocurrencia ligera. En su extensa biografia sobre el paisajista, Laura Wood Roper (1983) hace hincapié en su deseo de ser el primero 


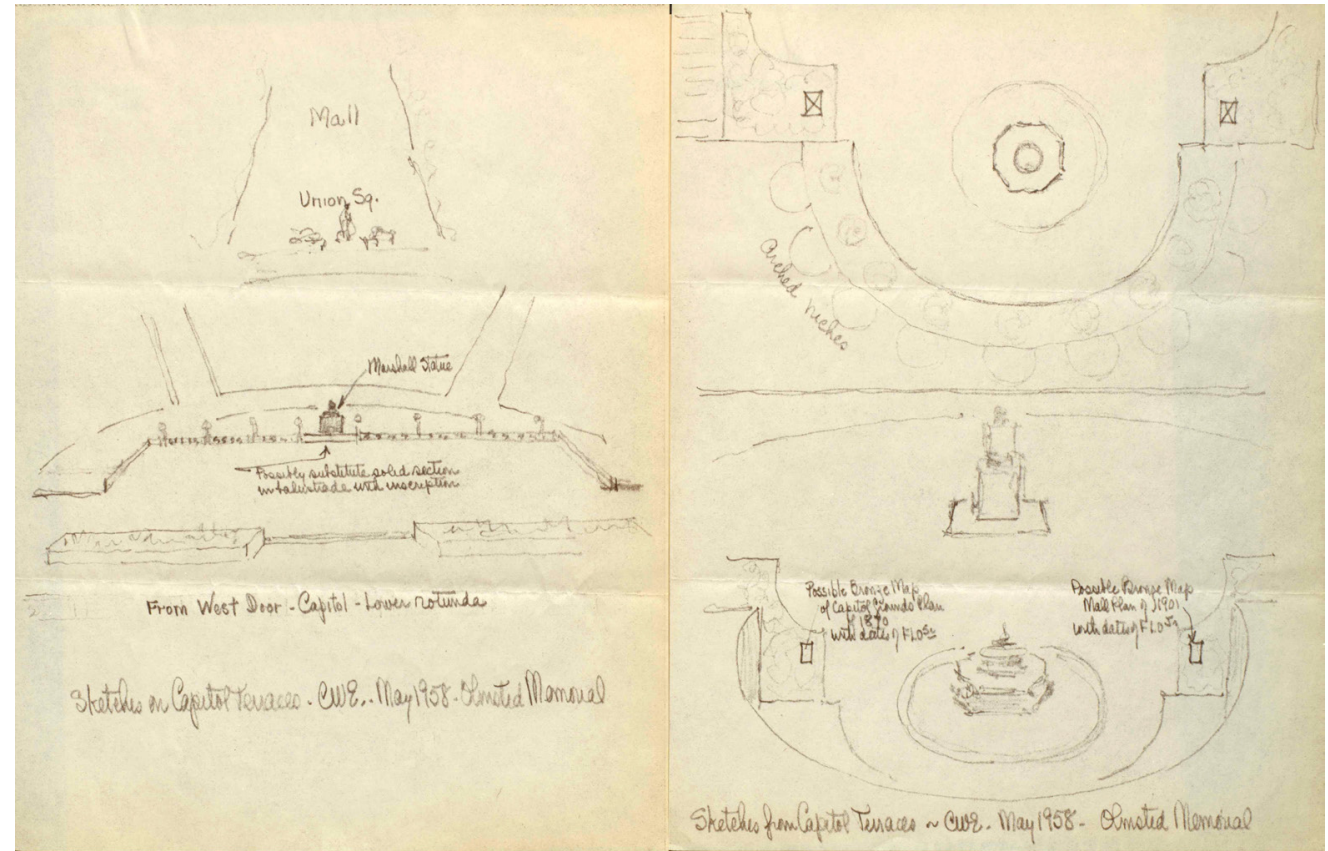

de una estirpe de paisajistas que mantuviera sus ideales e incluso su nombre. Es por ello que a su primogénito no solo se le cambió el nombre para llamarlo como a él, sino que fue educado desde la infancia para reemplazar a su padre. Este control de los Olmsted sobre el paisajismo estadounidense fue una realidad al menos durante la primera mitad del siglo $\mathrm{XX}$, hasta tal punto que "la aparición de la práctica profesional moderna se puede trazar a través del trabajo de este estudio familiar" (Klaus 1997: 80). Como muestra de la notoriedad que tuvieron, basta citar la base de datos informática de pioneros del paisajismo americano que el National Park Service elaboró a principios de 1990. En ella, se tuvo que evitar la inclusión de entradas para Olmsted y sus hijos porque los resultados que saldrian asociados a ese nombre serian demasiado altos, ya que "el número de diseñadores empleados por el estudio de los Olmsted fue tremendo" (Birnbaum y Crowder 1993: 3). Además, a esa cantidad habria que sumar aquellos "individuos que se graduaron en el curso [de paisajismo] de Harvard bajo la dirección de Frederick Law Olmsted Jr" (ibid.) y las colaboraciones profesionales con otros estudios

La estirpe de los Olmsted cobró tal importancia para los paisajistas de la sociedad que, a mediados del siglo XX, se propuso la realización de "un memorial conjunto al padre y al hijo en la terraza del Capitolio [de los Estados Unidos]" (Williams 1958). Así, Olmsted Sr., que diseñó los jardines de dicho edificio, y Olmsted Jr., que participó en la Comisión
McMillan, podrían ser celebrados junto a los Padres de la Patria en un lugar preeminente sobre el National Mall de la capital estadounidense. Charles W. Eliot II $^{5}$ incluso llegó a elaborar unos bocetos que dan una idea de lo que habría sido aquel monumento (figura 3).

No es de extrañar así que la ASLA fuera otro medio de influencia de esta familia sobre el paisajismo norteamericano. Es por ello que, siguiendo la observación de Nadenicek y Hastings (2000) citada en la introducción, se puede afirmar que la asociación se tornó un vehículo para conformar la profesión a imagen y semejanza de Frederick Law Olmsted. De hecho, el mismo Olmsted Jr. escribió, junto a Theodora Kimball, una biografia de su padre que a la vez conformaba al perfecto paisajista. Un documento de gran interés, en el que se nos dibuja a Olmsted como el profesional modélico de la arquitectura del paisaje:

Un campo en el que su ya reconocido talento para la expresión literaria pudo unirse, muy ventajosamente, con su apreciación escénica, su latente genio artístico y su conocimiento práctico como agricultor. (1922: 131)

Una atribución variada de conocimientos y funciones, y una elevada noción del paisajista, que ya nos permiten ver dos cuestiones. Por un lado, el principal problema con que se enfrentó la asociación: determinar un ámbito profesional claro. Por otro, el principal error que cometió: asociar el perfil de sus miembros a la conducta personal en vez de a la puramente profesional.
Figura 3. Bocetos de Charles W. Eliot II para el memorial de los Olmsted en el acceso al Capitolio de EEUU. 
Figura 4. Membrete de varios de los socios que muestra la discordancia en la denominación de la profesión.

\section{El nombre de la profesión}

La discusión y poca resolución de la sociedad asomaron la cabeza ya desde el mismo momento en que se quiso acordar el nombre de la profesión. En la actualidad, el origen de la expresión Landscape Architect (arquitecto del paisaje) y su evolución es un tema que ha sido muy tratado (Disponzio 2001 y 2014; Dümpelman 2014) y no es de extrañar que para la sociedad fuera un asunto de debate, ya que también lo fue en su momento para el propio Olmsted: "he llegado a tenerle aprecio, aunque me opuse mucho a él cuando me fue dado en primer lugar". (Olmsted [1888] 1922: 27)

Cuando Manning envió en 1895 la citada carta solicitando opiniones para formar la asociación encontró acuerdo en varias ideas. Sin embargo, se aprecia una clara discordancia en la denominación profesional de los interrogados. Encontramos, por ejemplo,
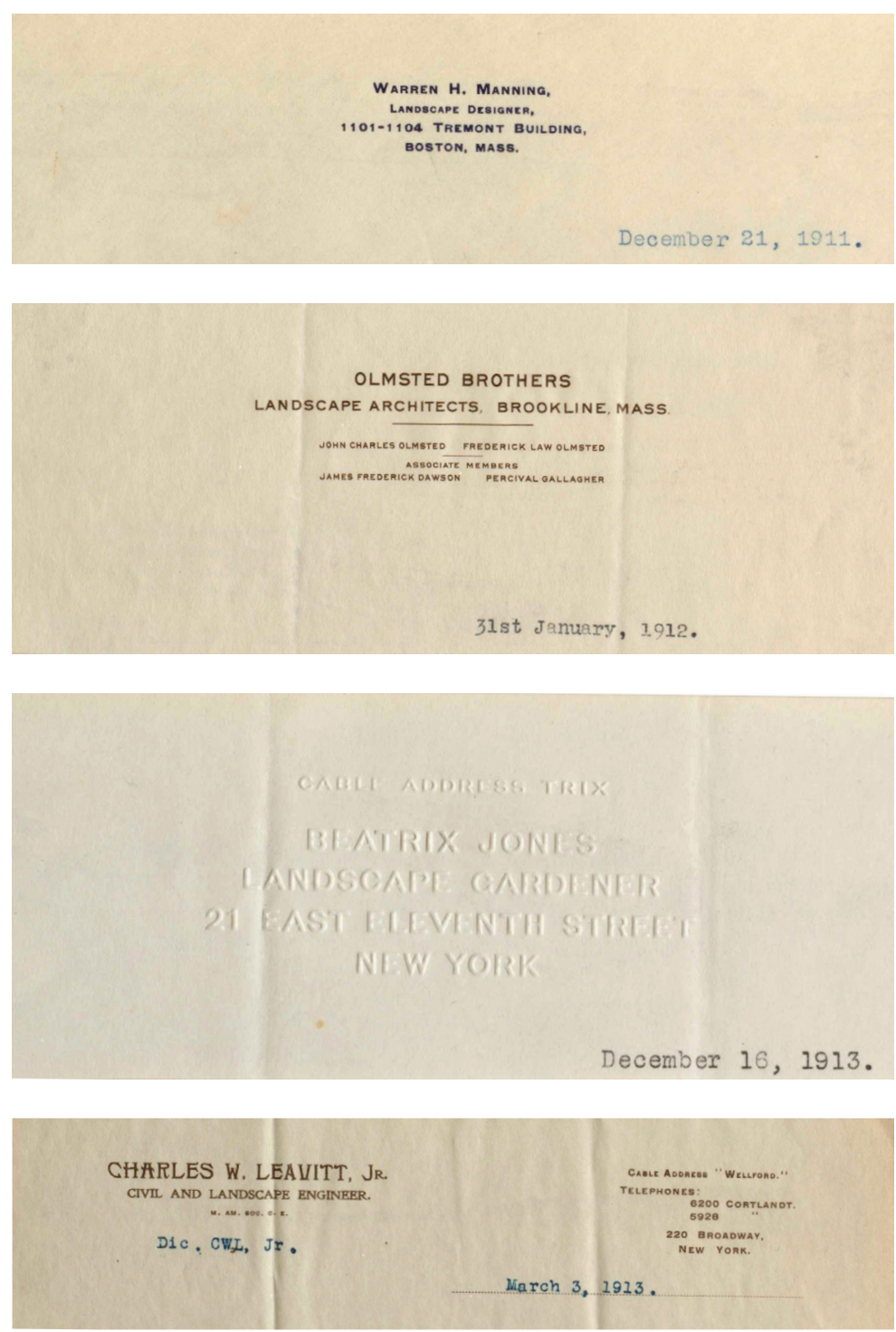

muchos Landscape Architects, pero también Landscape Engineers, Landscape Gardeners o Landscape Designers (VVAA 1895). El nombre que debía recibir la profesión fue un asunto prevalente durante décadas (figura 4). En 1905, F. L. Olmsted Jr. instó a demandar al propio Manning que explicara "el abandono por su parte del título Landscape Architect y su sustitución por el título Landscape Designer", aunque "quizás para muchos de nosotros eso sería remover el pasado". (Olmsted Jr. 1905)

Pero el asunto no sería tan antiguo cuando en 1910 se formó un comité "para considerar un cambio de nombre en la sociedad" (ASLA 1922a: 26) y en 1914, bajo la presidencia del mismo Manning, se llevó a cabo una votación que "pueda ayudar a la elección definitiva de un nombre común para la profesión" (Pray 1915). Muchos de los nombres propuestos se relacionaban con otras profesiones: Landscape -Architect, -Engineer, -Artist o Gardener. El resto fueron una referencia más genérica al trabajo con el paisaje: Landscaper, Landscapist, Landscape Designer o, la más curiosa, Landscape Man. Aunque las tres cuartas partes de los votos se inclinaron por Landscape Architect, se siguió considerando un nombre imperfecto:

[El voto] parece, en todo caso, demostrar que, a pesar de todas las desventajas del término "Landscape architect", la gran mayoría de la profesión está a favor de mantenerlo. (Hubbard 1914)

Manning, en su informe anual tras la votación, insistió en la importancia de que el nombre común para todos los profesionales del paisaje fuera algo propio. "Debería ser un nombre que no nos deje expuestos a las implicaciones de que estamos subordinados a otra profesión cuya denominación se incluye en nuestro nombre" dijo, refiriéndose sobre todo al término arquitectura: "una denominación que ha sido utilizada por esa otra profesión en su labor durante años." (Manning 1915)

El problema del nombre persistió y llegó a ser visto como una causa importante de la ausencia de reconocimiento público y de la falta de respeto por parte de otras profesiones. En 1925, al parecer, algunos paisajistas adoptaron el título de Landscape Engineer porque, si no, "no ganarian el necesario respeto del mundo profesional". El desacuerdo en el nombre llevó a que "nuestra profesión no se haya hecho lo suficientemente conocida" (Greenleaf 1925). Lejos de ser un tema superficial, el problema del nombre de la pro- 


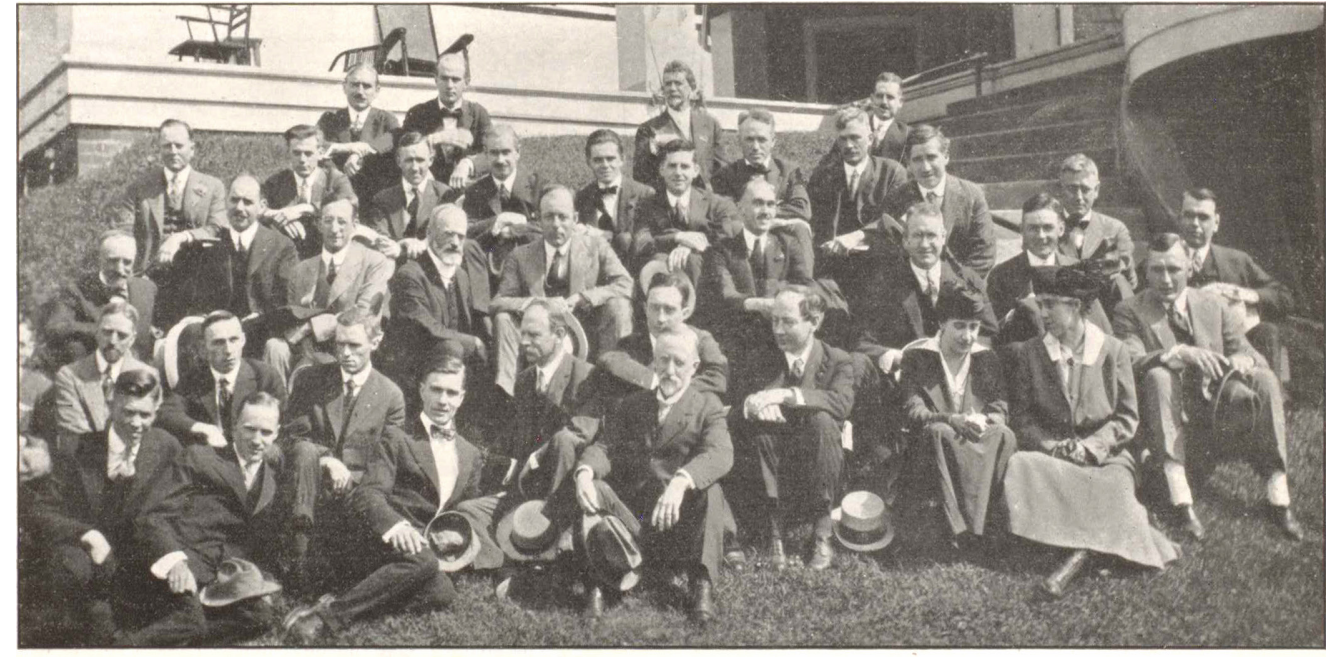

American Society of Landscape Architects, at the Portage Country Club. In the group are the most noted men in this line of work in this country. fesión ha sido visto recientemente como una de las claves fundamentales de su situación critica (Scazzosi 2004). Por ello, el desacuerdo en la ASLA para denominar definitivamente la profesión manifiesta en el pasado las mismas dudas presentes sobre qué es y a qué se dedica la arquitectura del paisaje.

\section{El cometido de la profesión}

Si la elección de un nombre común ya supuso cierta discordia, más lo hizo la determinación del ámbito profesional. Al ser la del paisajista una labor que abarcaba diversos cometidos y escalas, Charles Eliot aconsejó en 1895 que la asociación no debía de ser de profesionales, sino de gente de diversos ámbitos "cuyo deseo sea avanzar en el arte del paisaje" (Eliot en VVAA 1895: 1). Si la profesión se modeló a partir de la actividad de Olmsted, la ASLA se formó integrando a representantes de las diversas disciplinas que abarcaba dicha actividad.

Por ello es importante la advertencia que hizo John C. Olmsted durante las discusiones previas a la formación de la sociedad. "Hay muy pocos arquitectos del paisaje en todo el país que lleven a cabo la profesión de un modo estrictamente profesional", y los pocos "que pueden ser reconocidos como tales [...] han llegado a ella de formas muy variadas y diferentes" (Olmsted [JC] en VVAA 1895: 2). De esto, él deduce el que será uno de los principales conflictos de la asociación:

Sus puntos de vista en muchos de los principales problemas, naturalmente, discreparán tanto de los de los otros profesionales que tendrán dificil cooperar con ellos con tal grado de cordialidad como para asegurar el éxito a largo plazo de su asociación (ibid. 3.)

Aun así, bajo la presidencia del mismo J.C. Olmsted, la ASLA aprobó su Constitución, donde trató de definir la actividad profesional: "un landscape architect o un landscape gardener en sentido pleno es aquel que practica el arte de organizar el paisaje para su uso y disfrute" (ASLA 1912: 10). En el texto se advierte ambigüedad tanto a la hora de nombrar la profesión como de definir su cometido, reducido básicamente al ordenamiento del paisaje. "Es necesario prestar atención a la falta de organización efectiva de la profesión", reconoció Manning en un informe de 1911, y

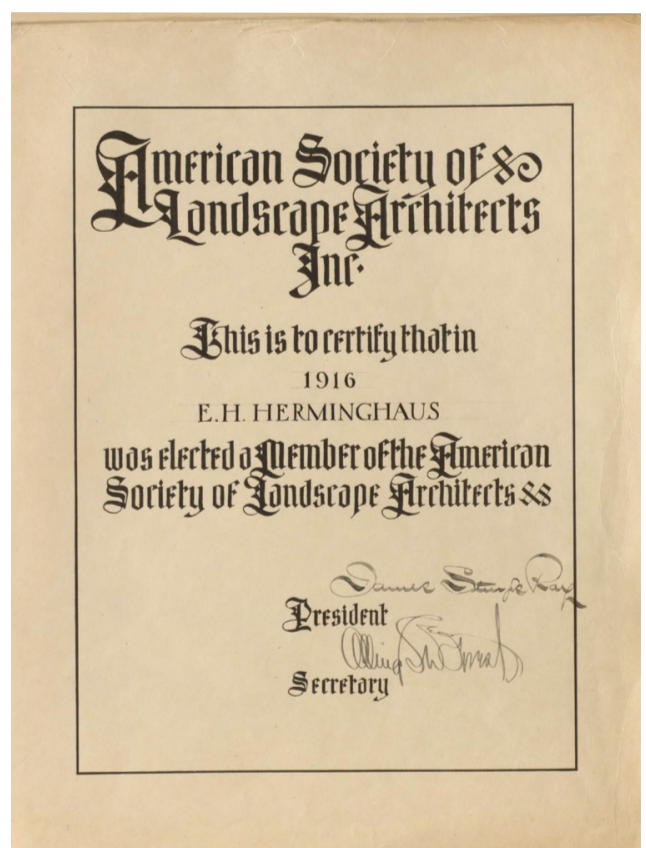

Figura 5. Miembros de la ASLA en una reunión sobre planeamiento urbano en la ciudad de Akron. La fotografia, que se muestra aquí con el pie original, apareció publicada en 1916 en el boletin oficial de la Cámara de Comercio de Akron.
Figura 6. Certificados de la ASLA en 1916. 
expuso la necesidad de "[luchar] por un reconocimiento público mayor". Pero el verdadero problema a destacar fue que el cliente no supo cuándo tenía que acudir al paisajista, y se produjeron solapamientos de competencias: "Muchos arquitectos están llevando a cabo las tareas propias de los ingenieros y los paisajistas en sus proyectos" (ibid.)

Las respuestas a dicho informe fueron aún más elocuentes en estos aspectos. "La profesión apenas se reconoce aquí como una profesión", respondió una paisajista, y más adelante: "No hay un entendimiento claro del ámbito profesional de nuestro campo. Por norma, los arquitectos no tienen ninguna consideración por nuestra profesión" (Bullard en VVAA 1911: 1). Por su parte, otro miembro aseguró que:

Estamos lejos aún de representar, a ojos del público, una clase profesional enteramente distinta de la de los arquitectos, ingenieros, horticultores, etc. Esto se debe probablemente al hecho de que estas profesiones [...] se presentan como capaces de llevar a cabo trabajos públicos o privados de paisajismo. (Vitale en VVAA 1911: 6)

El ámbito pretendido para la arquitectura del paisaje era tan amplio que se solapaba con el de otras disciplinas. Por tanto, en los primeros años de la sociedad, se dio la preocupación constante de distinguirse de los ingenieros y, sobre todo, de los arquitectos. Estos últimos no solo contaban con una asociación más longeva, el American Institute of Architects, fundada en 1857 , sino que, adeprincipios de la ASLA entre 1914 y 1940.

\section{DECLARACIONES DE PRINCIPIOS}

\begin{tabular}{l|l}
\hline $\begin{array}{l}\text { Iniciales 1914 - 1920 } \\
\text { (Comité Ejecutivo 1914; } \\
\text { Comité Ejecutivo 1916; } \\
\begin{array}{l}\text { Junta Directiva 1917; } \\
\text { ASLA 1922a:47) }\end{array}\end{array}$ & $\begin{array}{l}\text { Preservación de las cataratas del Niagara } \\
\text { Construcción en parques públicos } \\
\text { Venta de suelo en parques } \\
\text { Vallas publicitarias } \\
\text { Parques Nacionales }\end{array}$ \\
\hline $\begin{array}{l}\text { Añadidas en 1922 } \\
\text { (ASLA 1922b) }\end{array}$ & $\begin{array}{l}\text { Bosques Nacionales } \\
\text { Compra oportuna de suelo para parques } \\
\text { Encargos estatales para las Artes } \\
\text { Vivienda } \\
\text { Planeamiento urbano }\end{array}$ \\
\hline $\begin{array}{l}\text { Añadidas en 1926 } \\
\text { (ASLA 1926) }\end{array}$ & $\begin{array}{l}\text { Memoriales públicos } \\
\text { Parques públicos }\end{array}$ \\
\hline $\begin{array}{l}\text { Añadidas en 1940 } \\
\text { (ASLA 1940) }\end{array}$ & $\begin{array}{l}\text { Planeamiento regional } \\
\text { Naturaleza comunitaria } \\
\text { Conservación de la belleza escénica } \\
\text { Contaminación atmosférica } \\
\text { Periferia urbana } \\
\text { Carreteras }\end{array}$ \\
\hline
\end{tabular}

más, su profesión tenía una historia mucho más antigua y el público en general tenía una idea clara de su cometido social. Por eso, la ASLA desde el principio trató de comprender lo que en 1903 llamaron "la relación ideal entre la Arquitectura y la Arquitectura del Paisaje" (ASLA 1912: 20 y también Walker [1908] 1912: 103).

A pesar de ello, la relación fue más conflictiva que ideal. La ASLA no favoreció ninguna iniciativa que sometiera al paisajista y subordinase su profesión, es decir, evitaron cualquier acción que convirtiese a la arquitectura del paisaje en un arte aliado hijo de la arquitectura (Borie y Trask 1906) ${ }^{6}$. El conflicto se fue haciendo más evidente con el avance del siglo y la sociedad llegó incluso a formar un comité específico que confrontase ambas profesiones, "para definir sus ámbitos de responsabilidad y mostrar tanto sus solapamientos como aquellas instancias en las que se deberian mantener separadas". (Vitale 1927)

Las Declaraciones de Principios de la ASLA (1914-1940)

La Primera Guerra Mundial (figura 5) supuso un momento crítico: "Como profesión, la arquitectura del paisaje es tan joven e incomprendida que se hace necesaria una definición clara de su propósito, espíritu y ámbito" (Child 1916). Para afrontar este problema se llevaron a cabo varias acciones, entre las que destaca, por un lado, una definición más completa del paisajista:

Un Landscape Architect [...] es un profesional que domina los asuntos relativos a la tierra [land] y a los trabajos humanos derivados de ella; su propósito singular es: belleza en lo aparente y utilidad. El paisajista realiza proyectos que combinan adecuadamente con la preservación, el incremento o la creación de la belleza. (Ibid.)

Por otro lado, la sociedad se organizó de manera más sistemática, se editaron certificados para los socios (figura 6) y se corporativizó en 1917, con la nueva denominación American Society of Landscape Architects, Inc. También se constituyó una Junta Directiva que la gobernara. Este organismo enseguida demandó "declaraciones precisas acerca del propósito y el ámbito de la arquitectura del paisaje" y también:

Que se habrán de declarar ciertos "Principios" [policies] en aquellos campos en los que nuestra profesión se encuentre en excepcional 
situación de ofrecer servicios al público, y que, junto a material cuidadosamente seleccionado, se habrán de poner a su disposición con un propósito publicitario. ${ }^{7}$ (Pray 1917)

Estas declaraciones son el único documento de la ASLA que realmente trató de delimitar un ámbito de actuación del paisajismo. En origen, tuvieron el objetivo de mostrar a la sociedad en general el enfoque profesional del arquitecto del paisaje, es decir, concretar su cometido de cara al público. Como con todos los asuntos que trataba la asociación, este se acabó volviendo un continuo discurrir de diversas opiniones y enfrentamientos. "[A este respecto] llevamos ya tantas cartas que parece que estuviéramos escribiendo la constitución de los Estados Unidos", observó sobre la declaración de principios Henry Vincent Hubbard (1914b), por aquel entonces tesorero de la sociedad.

El proceso de identificación de los ámbitos del paisajista fue lento y confuso. Como podemos ver en la tabla 1, sobre estas muestras de interés hubo varias revisiones y se añadieron nuevos elementos con el avance del siglo. En lo que se refiere a la concreción del ámbito profesional, es interesante ver cómo los distintos acontecimientos históricos fueron moldeando y dirigiendo la profesión hacia nuevos campos. Pese al ya mencionado deseo de definir con claridad su propósito, espíritu y alcance, el campo del paisajismo siguió con el espiritu de Olmsted y fue integrando áreas de actuación según surgían, en una continua redefinición de la profesión.

Como vemos en la tabla, las primeras muestras de interés se centraron sobre todo en la preservación; no estuvieron referidas al diseño propositivo del paisaje, sino a su conservación. Se concretaron principios sobre el mantenimiento de los parques nacionales, sobre el control de la venta de suelo y la construcción de nuevas edificaciones en parques públicos, y sobre el efecto de las vallas publicitarias para la calidad escénica de determinados paisajes. Esto contrastaba con la actividad profesional que los miembros de la asociación llevaban a cabo fuera de esta, enfocada a la creación de sistemas de parques, planes urbanos y suburbios. No fue hasta después de la Primera Guerra Mundial que estas actividades se empezaron a trasladar a las declaraciones de principios de la ASLA. Como muestran las palabras de James Pray, presidente durante la mayor parte del conflicto bélico, el paisajismo se revitalizó tras la contienda:

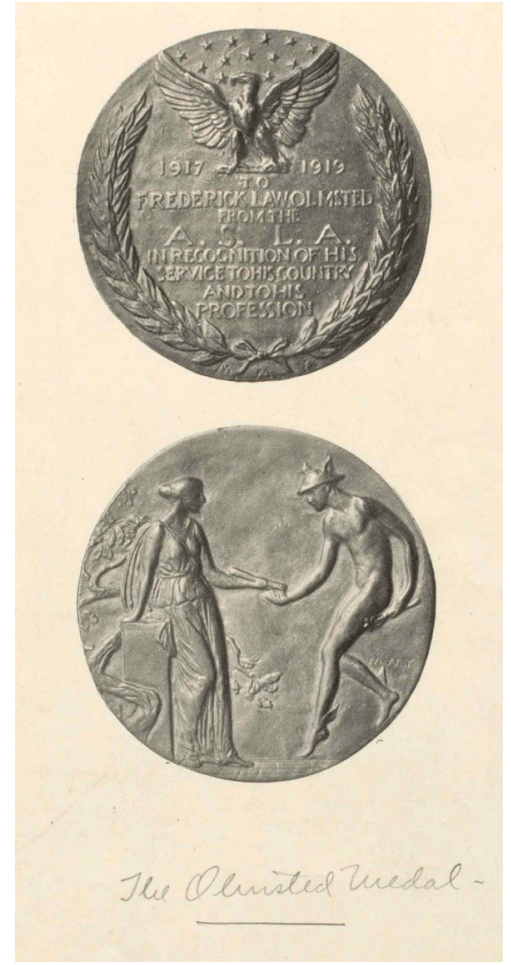

Figura 7. Medalla ofrecida por la ASLA a Frederick Law Olmsted Jr. en 1922.
Éramos una profesión débil y en apuros, eclipsada (aunque nos negáramos a aceptarlo) por las otras profesiones más antiguas y poderosas, hasta el punto de tener que justificar constantemente nuestra existencia individual y nuestra organización. Durante este año, hemos tenido la oportunidad de demostrar [...] en un tiempo de necesidad de nuestro pais, que los hombres entrenados para diseñar el medio terrestre con fines prácticos, a la vez que para alcanzar la belleza, pueden ofrecer el máximo servicio público tanto en la guerra como en la paz [...].

Nuestra participación en este servicio ha llevado muy lejos la relación con las profesiones que más intimamente se nos asocian de la ingeniería y la arquitectura, con ellas estamos ahora en una posición de cooperación nunca antes vista [...] Esto ha sido posible, en primer lugar, gracias a la feliz iniciativa, habilidad y generosa devoción de uno de nuestros miembros, Frederick Law Olmsted [Jr.]. (Pray 1919)

El texto se cita aquí de manera extensa porque muestra varios aspectos destacados para la sociedad. En primer lugar, se percibe la recuperación de la función patriótica que tan importante fue para F.L. Olmsted Sr. (Roulier 2017). La utilidad de los paisajistas durante la Primera Guerra Mundial hizo que estos superasen un complejo de inferioridad que les hacia verse menos útiles para la sociedad que otras profesiones afines. En segundo 
lugar, es interesante notar que esta renovada confianza en la profesión se debió a otro F.L. Olmsted, esta vez el hijo. Las palabras de Pray muestran algo trascendental para una asociación que puso mucho énfasis en la retórica y el simbolismo: la profesión se revitalizaba cuando la utilidad social del paisajismo, a través del servicio a la patria, se ligaba con el nombre de Frederick Law Olmsted.

Como presidente del comité ejecutivo de la "National Conference on City Planning", asî como en su trabajo en la Cantonment Division y el Bureau of Industrial Housing, Olmsted Jr. supo ver la necesidad de nueva vivienda que traería la guerra. Detectó que "la expansión de los sectores directamente conectados con la guerra supondrá la concentración de varios miles de hombres" (Olmsted Jr. 1917a), y que, por lo tanto, se requeriria un gran número de profesionales del planeamiento espacial. Por esto urgió a la ASLA a "encontrar qué servicios específicos pueden ofrecer los miembros en la presente emergencia nacional" (Olmsted Jr. 1917b). Con ello, logró que los miembros de la asociación contaran con un gran número de contratos gubernamentales.

Las muestras de agradecimiento a Olmsted Jr. tras esto fueron constantes. En un discurso ante la ASLA, el secretario de la "National Conference on City Planning", expresó: "Si me permiten, por un momento, usar un lenguaje bíblico, [FLO Jr] nos ha sacado del salvaje mundo de las opiniones encontradas y

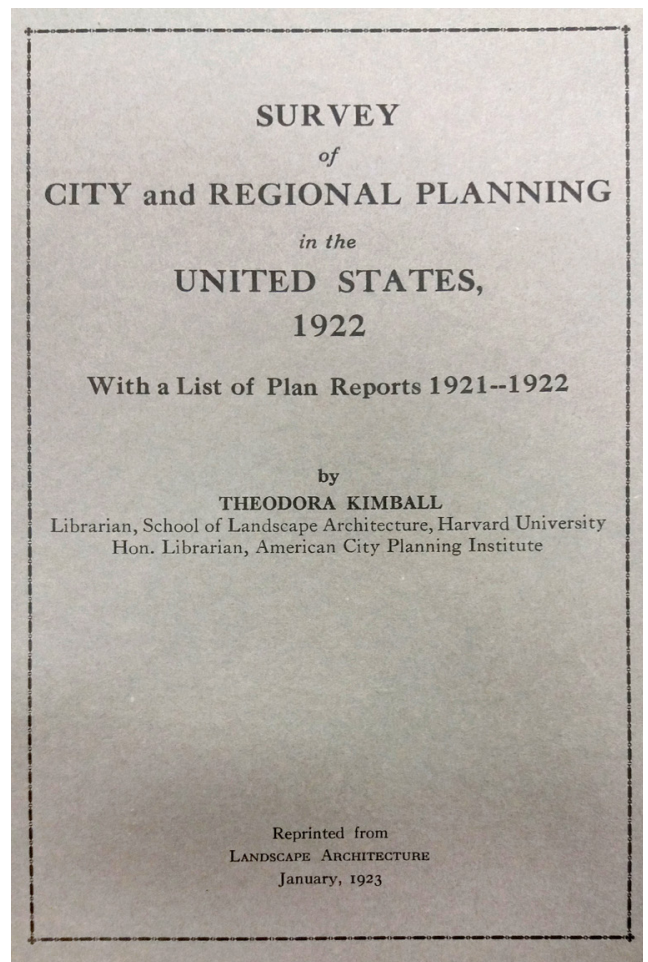

nos ha guiado hacia nuestro camino" (Shurtleff 1914: 144). También en su última reunión de 1918, año en que finalizó la contienda, la ASLA se reconoció "privilegiada por poder haber servido profesionalmente en estas tareas de planeamiento de tan alta responsabilidad" y "por esta oportunidad, los miembros de la sociedad están fundamentalmente en deuda con los impulsos patrióticos de Frederick Law Olmsted [Jr.]" (ASLA 1922a: 43). Ese mismo dia, la asociación le entregó una medalla "en reconocimiento por sus servicios a su país y a su profesión" (figura 7).

Después de la guerra, F.L. Olmsted Jr. presidió la ASLA y se enfatizó el planeamiento urbano como opción profesional para los paisajistas. En esta época, se forma un comité específico sobre Town Planning and Industrial Housing y Theodora Kimball, la coordinadora de la biblioteca de la Escuela de Arquitectura del Paisaje de Harvard, escribió durante un tiempo un reportaje anual sobre City Planning in the United States $^{8}$ (figura 8). Además, desde Bélgica se solicitó consejo a la ASLA sobre cómo rehabilitar las ciudades devastadas por la guerra, y la sociedad envío en 1923 a un miembro a la "International Town Planning Conference and Exhibition" en Gotemburgo, donde, entre otros participantes, estuvo presente Raymon Unwyn.

Por supuesto, también en esa época, la ASLA incorporó a sus Declaraciones la vivienda y el planeamiento urbano, dos objetivos del paisajista que a esas alturas ya habian sido asimilados como un refuerzo de su identidad y utilidad social. "No hay ninguna razón fundamental por la cual los arquitectos del paisaje no debieran estar en la dirección del planeamiento urbano", dijo a este respecto James Greenleaf (1924), en el año en que sustituyó a Olmsted Jr. en la presidencia de la ASLA. Por otro lado, la Primera Guerra Mundial aumentó la demanda de monumentos bélicos públicos, otro aspecto patriótico que se conviertió rápidamente en política de la asociación en 1926.

El Crac del 29 y la posterior crisis, a pesar de reducir las arcas de la asociación, reforzaron la deriva profesional del paisajista hacia labores más técnicas (figura 9). Las políticas del New Deal propuestas por Franklin D. Roosevelt y, sobre todo, el National Industry Recovery Act (NIRA), crearon la idea de que la "arquitectura del paisaje puesta al servicio del gobierno es de gran valor para la profesión" (Hall c. 1933). Esto dio lugar a un conflicto que tenía como raíz la misma definición de la arquitectura del paisaje. Algunos miem-
Figura 8. Portada de uno de los informes que realizó Kimball sobre planeamiento en EEUU. 
bros protestaron por la estandarización excesiva de la profesión que requería trabajar con el gobierno "porque tendemos a ceder nuestra autoridad ante la noción de que se nos puede regular mediante un código" (Hubbard 1933). Otros, sin embargo, afirmaron todo lo contrario: "Una definición positiva de lo que es la arquitectura del paisaje [para] establecer esto como una vara de medir como referencia en casos futuros". (Stevenson 1934)

Aunque el NIRA se declaró inconstitucional en 1935, la ASLA continuó centrándose en la infraestructura y el planeamiento a gran escala. En su Declaración de Principios de 1940, se añadió el planeamiento regional, que incluye la interrelación de "problemas de comunicación mediante carreteras, ferrocarril y medios acuáticos y aéreos, y los principales suministros de agua, desagüe, alcantarillado, luz y sistemas energéticos" (ASLA 1940: 10). Además, se incluyó, entre otros, el tratamiento de la periferia urbana y, como antecedente del movimiento ambientalista de la segunda mitad del siglo XX, una preocupación por la polución atmosférica.

Las aspiraciones del paisajismo como una profesión totalizadora se dejaron ver mejor que nunca en el texto introductorio de esta última Declaración de Principios. Se demandó "un mayor reconocimiento del arquitecto del paisaje" ya que "sus funciones conciernen todo lo exterior; no hay nada iluminado por el sol que, de un modo u otro, en el presente o el futuro, no forme parte de su cometido" (ASLA 1940: 1). A pesar de todo, esta confianza, más que definir el ámbito profesional, lo acabó desdibujando:

Ahora tenemos al estudio de los Olmsted designándose como "Land Planning and Landscape Architecture". Mi estudio se denomina "Landscape Architecture and Town Planning". [...] Muchos otros se designan como Landscape Architects y otras formas de planeamiento, en un esfuerzo para ampliar el ámbito de sus actividades en la mente de los posibles clientes y el público en general. (Taylor 1943)

La Junta Directiva de la ASLA, por su parte, observó, de nuevo, "una falta de unificación en el propósito y entendimiento de la profesión y de los problemas que la conciernen" (Chambers 1943). Esto llevó, al igual que en sus inicios, a plantear la posibilidad de un cambio de nombre para la sociedad. Así, ninguno de los intentos de definición profesional evitó que las mismas dudas de principios de siglo le surgieran al presidente de la sociedad cuarenta años después: "Si el nombre de la sociedad se ha de cambiar, ¿qué nombre es preferible?”. (Hare 1943)
Figura 9. Cuadro sobre las tareas que podia desempeñar un arquitecto del paisaje en las ramas del National Industry Recovery Act. Publicado originalmente en "Landscape Architecture, A quaterly" vol. XXIV, n ${ }^{\circ} 2$ (enero, 1934).

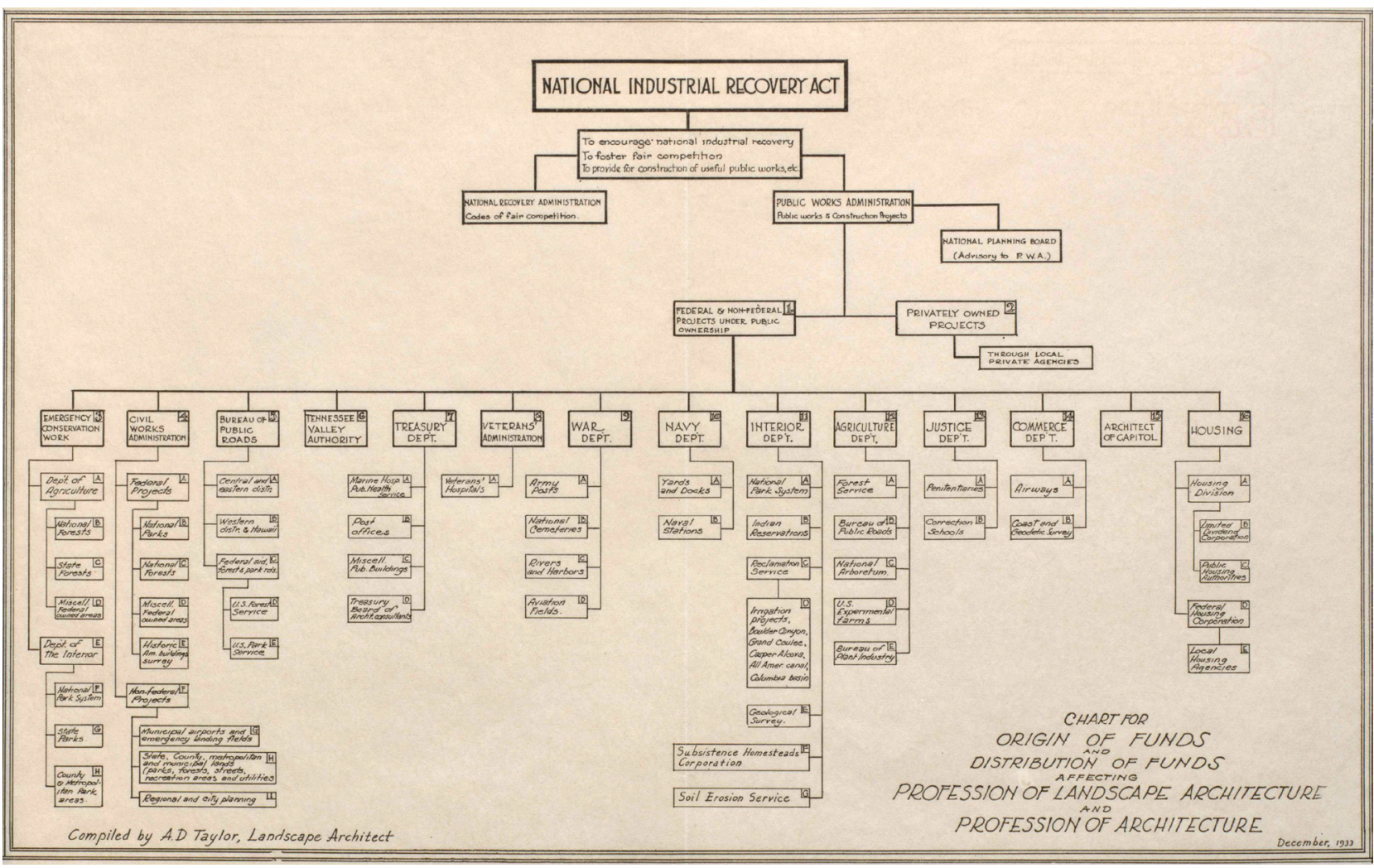




\section{La definición del profesional}

Como hemos visto, el amplio rango de aplicaciones que tenía la práctica del paisajismo desdibujó la profesión en relación a otros ámbitos. Las dificultades para concretar un nombre y un campo profesional derivaron tanto de la compleja naturaleza de la arquitectura del paisaje como del poco éxito que tuvo el continuo proceso negociador dentro y fuera de la ASLA. Sin embargo, el único punto que nunca se discutió, referido al perfil profesional, tuvo igualmente consecuencias negativas para la profesión.

Si volvemos de nuevo a la última década del XIX, al conjunto de respuestas que recibió la solicitud fundacional de Manning, vemos que, aunque existe conflicto respecto a qué es el paisajismo, no lo hay en cuanto al respeto que merece y las expectativas de su trascendencia. "Si el paisajismo se ha de convertir en nuestro arte nacional, nada acelerará más la llegada de ese día que una organización como la que se propone", comentó William W. Parce (VVAA 1895: 8). Por tanto, la asociación nació con el deseo de ser algo más que un conjunto de profesionales: un medio de moralización que pudiera "dar peso a los más altos ideales" $(4$ [Baxter $])^{9}$ e "influir sobre el gusto del público en la dirección correcta" (5 [Simonds]). Tal sociedad, por tanto, había de ser formada por "apóstoles del buen gusto" (8 [Bullard]), una élite selecta capaz de "despertar a las masas [y] educarlas en aquellos principios que [...] sean productores de bondad". (8 [Collins])

Las respuestas coincidieron también en que, para cumplir tales expectativas, el correcto proceder era "restringir la afiliación" para que la "asociación pueda mantenerse en un plano superior a aquel en el que estaría si buscara un incremento de sus miembros" ( 6 [Simonds]). De formarse la sociedad, el ingreso deberia quedar restringido a "las personas más capaces y generosas" (7 [Shinn]), "artistas genuinos" (4 [Van Rensselaer]), "hombres que estén interesados en la mejora de lo público como fin en sí mismo". (6 [Robbins])

Esta noción tan elevada del paisajista se intentó enraizar en una serie de modelos históricos, entre los que prevaleció la figura de Olmsted. A este, no solo se consideraba un gran artífice del paisaje, sino una persona de entereza moral y recto proceder (Kalfus 1981). Por supuesto, su figura se había idealizado siguiendo cierta lógica inversa. Cuando la ASLA definió la arquitectura del paisaje lo hizo con el pleno convencimiento de que, en el nombre de la profesión, la palabra arquitectu- ra "se usó siguiendo el significado más amplio de Milton, referido al Todopoderoso como 'el arquitecto del mundo', su maestro creador" (Child 1916). Si Olmsted fue el modelo sobre el cual se creaba dicha disciplina, no podía ser menos que un ser elevado.

La compleja articulación de labores y escalas que había de lograr el arquitecto del paisaje hizo difícil encontrar otros paisajistas que hubieran obrado de forma similar. A esto habia que sumar, además, que sus obras tenian que tener un valor social democrático cercano al que pretendía la ASLA. En una de sus reuniones, Ferrucio Vitale, en un intento por demostrar la validez del jardín italiano como modelo, ensalzó el valor de los jardines de la Toscana por ser esta tierra un lugar que "nunca ha tenido nobleza de sangre, y toda su historia es una historia de democracia" (1905: 38). Por otro lado, Stephen Child, alabó el jardín inglés ya que el "diseño de paisaje inglés fue por norma más humano" (1911: 18) que el de Andre Le Nôtre, cuya axialidad y motivos formales comparó con la obra de otros franceses como Jean-Charles Alphand, ÉdouardFrançois André y Pierre Charles L'Enfant ${ }^{10}$.

$\mathrm{Al}$ igual que con los miembros potenciales de la ASLA, los referentes históricos no fueron solo evaluados por la calidad de la obra, sino por el carácter de su autor. De entre los paisajistas ingleses, el mismo Child desdeñó a William Kent, "quien poseía cierto talento artístico pero poca cultura", y a Capability Brown, a quién describió como un "jardinero al que por asociarse con hombres refinados [...] se elevó hasta un lugar honorable". Sin embargo, a Humphry Repton sí le consideró un adecuado modelo a seguir: "Podemos perfectamente prestar atención a sus palabras ya que fue un gentleman inglés culto, de gran refinamiento y buen gusto" (1911: 6); es decir, un buen paisajista.

Esta predilección por Repton hizo que en 1907 se escogiera su libro The art of Landscape Gardening (figura 10) como el primero de una colección de clásicos reeditados que permitiera crear "una biblioteca autorizada de arquitectura del paisaje" (ASLA 1912: 26). El objetivo de estas publicaciones fue afianzar en el pasado la profesión de la arquitectura del paisaje, demostrando tanto la pertinencia de su cometido como sus fundamentos morales:

La reimpresión de trabajos como el de Repton [...] ayudará a demostrar al público en general que el arte al que estamos dedicados es una de las bellas artes, fundada en grandes 
principios que, en el pasado, han tenido una amplia aplicación y que, en el futuro, si seguimos haciendo cosas magnificas y permanentes, incrementará su prevalencia. (ASLA 1912: 27)

\section{El acceso a la ASLA}

Una vez fundada la sociedad, el órgano encargado de seleccionar a miembros tan altamente cualificados fue la Junta Examinadora. Su deber fue "conocer la habilidad profesional y entrenamiento de los aspirantes a ser elegidos"; para ello pidieron "varios ejemplos del trabajo del aspirante, acompañados de explicaciones escritas" (Examining Board 1910). Como vemos en la figura 11, al solicitante se le exigió tanto una elevada calidad profesional como personal. La Junta Examinadora se encargó de juzgar la labor y la honradez del paisajista, lo cual le aportó un estatus muy elevado. Esto se reflejó claramente en la introducción a su informe del año 1910, en donde describieron su trabajo con una retórica cargada de simbolismo:

Nos vemos a nosotros mismos como filántropos -filántropos de la clase más alta- ya que nuestra empresa es elevar a nuestro prójimo. Durante los últimos doce meses, nuestra labor altruista ha tenido los siguientes resultados:

Hemos llevado a cuatro hombres desde la oscuridad a la calidad de Miembros Jóvenes de la Sociedad.

Hemos coronado con aureolas las cabezas de siete miembros que han sido elevados al nivel de Miembros Activos: les rogamos que mantengan esas aureolas brillantes. (Greenleaf 1911)

El escrutinio de la información presentada por los solicitantes fue muy elevado. En el mismo documento se informó de que su labor no era "simplemente suponer la adecuación de cada solicitante, sino conocerla". Se atribuyeron así una responsabilidad capital ya que "la afiliación a la sociedad se vuelve cada vez más apreciada” (ibid.). Bajo la atenta observación de la Junta Examinadora, el acceso a la ASLA fue, desde el principio, restringido y el rechazo elevado (figura 12).

Esta situación condujo al malestar entre los asociados. "¿Puede decirme por favor por qué la American Asociation of Landscape Architects, Inc., es tan cautelosa al seleccionar nuevos miembros?" preguntó Charles W. Eliot al presidente de la asociación en 1923,
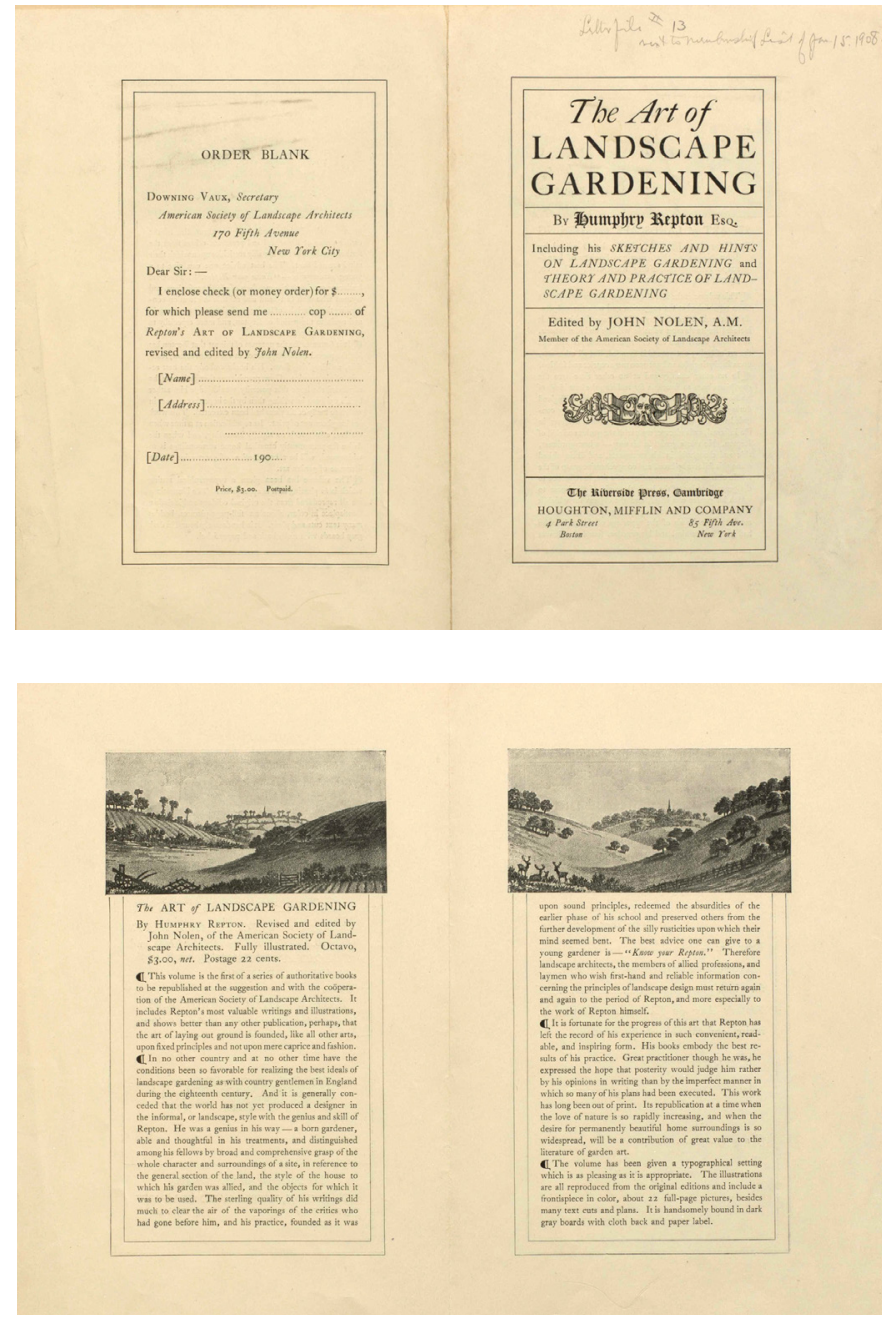

a la vez que advirtió de que eso les impediría progresar. Eliot, que fue presidente de la Universidad de Harvard durante cuarenta años y uno de los propulsores del primer curso de Arquitectura del Paisaje, estuvo muy interesado en promover la incorporación de jóvenes que acrecentaran las filas de la asociación. Lo demuestra su insistencia sobre el asunto:

¿Es el propósito de la Sociedad convertir la afiliación en algo que aporte experiencia de primera categoría para el trabajo del arquitecto del paisaje y cierto éxito profesional? La mayoría de las sociedades que sirven a las antiguas profesiones, o a las nuevas, no aspiran a ser selectivas sino, al contrario, inclusivas, con la esperanza de que la sociedad pueda ser igual de útil a los hombres menos experimentados que a aquellos con más experiencia. (Eliot 1924)

Como respuesta a este planteamiento, obtuvo una larga carta recordando la necesidad de "mantener altos los estándares para la admisión, a menos que nos queramos ver
Figura 10. Folleto de la ASLA para publicitar la reimpresión de 1908 de "The Art of Landscape Gardening", de Humphry Repton. 
invadidos por todo tipo de charlatanes e ineptos" (Pray 1924). Términos estos que recuerdan a los utilizados por Olmsted Sr. en una carta en la que describe a tres personas no recomendables para el paisajismo por ser, respectivamente, un "granuja", un "estafador" y un "ignorante” (Olmsted [1888] 1922: 130). La práctica paisajística se vio así dividida en dos. Por un lado, una profesión sabia y honesta, que buscaba embellecer los lugares a la vez que resolver sus problemas funcionales, $y$, por otro, un quehacer indecente que buscaba el enriquecimiento rápido y poco atento a los valores estéticos y operacionales. "Hay toda la diferencia del mundo entre el Verdadero Arte del Arquitecto del Paisaje... y el llamado Ser- vicio Paisajístico" (figura 13), afirmó un anuncio en una popular revista sobre jardinería.

Sea como fuere, lo cierto es que el alto estándar profesional que la ASLA pretendió de sus miembros la llevó a una situación crítica. En el mismo 1924 un miembro solicitó que se acrecentara el número de asociados, alegando que "sufrimos continuamente porque no podemos cumplir con los programas que iniciamos, debido a que no hay suficientes miembros a los que recurrir para hacer el trabajo" (Schermerhorn 1924). Según él, esto llevaba a una situación de falta de progreso de la asociación y falta de reconocimiento social. A ello se sumó la falta de ingresos por las cuotas que limitó las finanzas de la asociación

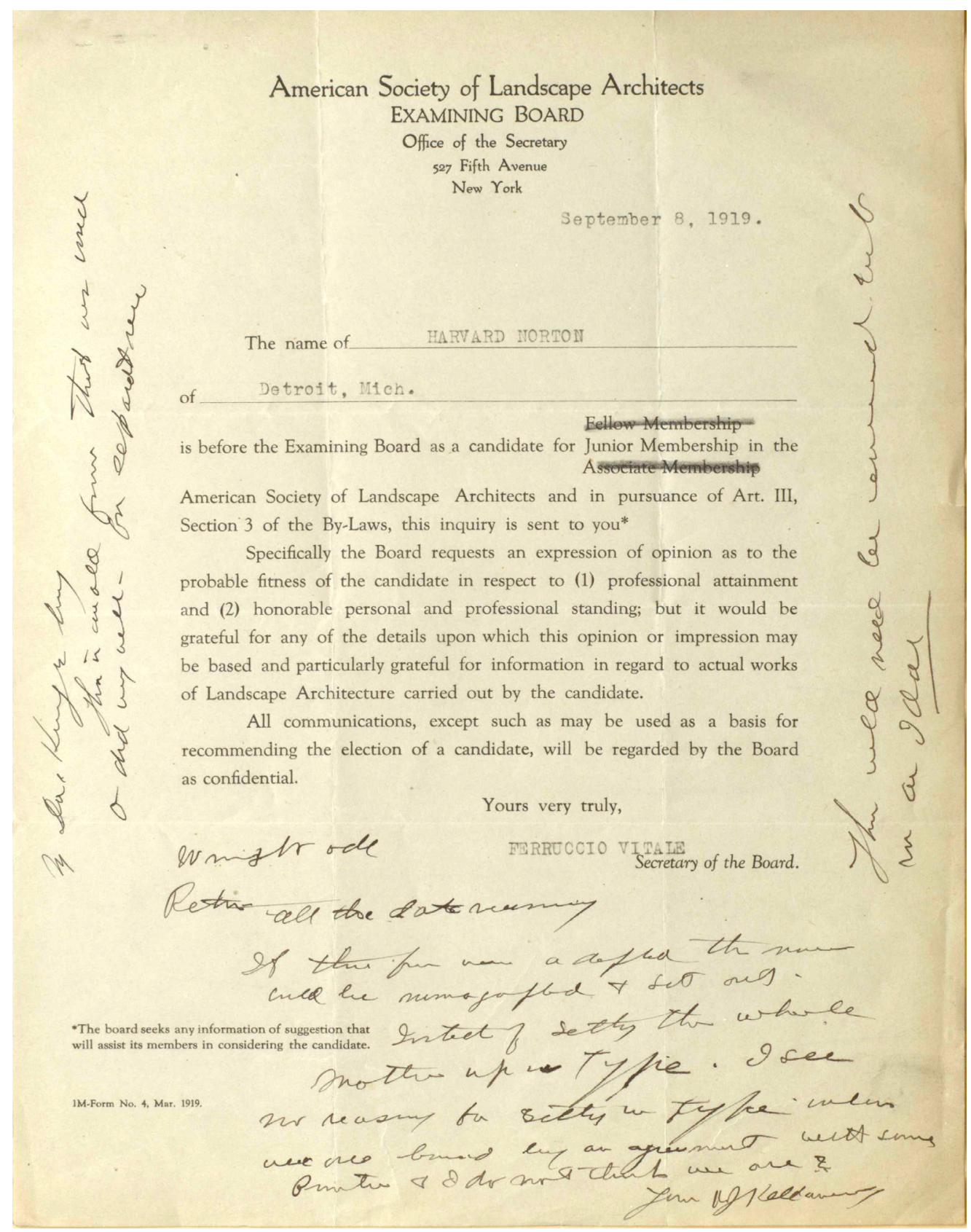

cripción en la ASLA. 
y, también, la distribución geográfica de los miembros, cuya lejanía hizo difícil alcanzar un quórum en las reuniones y mantener el control de las actividades (figura 14).

\section{Epilogo}

En el artículo se esbozan una serie de nociones y problemas relacionados con la arquitectura del paisaje que van más allá de lo meramente anecdótico. Durante más de cuarenta años, la sociedad dedicada a dar forma a la profesión se vio con serias dificultades tanto de carácter interno como externo. Las aspiraciones heredadas para una profesión que se había conformado de manera contingente entraron en colisión con el auge del Movimiento Moderno, la estandarización profesional, el cuestionamiento de la tradición histórica en las artes plásticas y aplicadas y su intensa revisión estilística.

David Schuyler (1986) ha explicado el trabajo de Frederick Law Olmsted Sr. como una respuesta a las necesidades urbanas del siglo XIX. Mientras que el diseño del jardin habria sido una disciplina adoptada por la necesidad de tratar elementos botánicos, el verdadero interés de Olmsted fue combatir la metrópolis capitalista con otros modelos urbanos. Por tanto, el paisajismo, en su concepción, no estuvo tan vinculado al diseño del jardín como al urbanismo. Esta noción prevaleció en muchos de los paisajistas de principios del siglo $\mathrm{XX}$, hasta el punto de que a Olmsted Jr. se le considera como uno de los padres fundadores del planeamiento urbano moderno en los Estados Unidos (Peterson 2003).

En este contexto, la Primera Guerra Mundial es un evento capital para la arquitectura del paisaje. La alta tecnificación y sistematización de labores con que se tuvieron que enfrentar los paisajistas inició la separación disciplinar entre el Landscape Architecture y el City Planning. La escisión fue promulgada sobre todo por Henry Vincent Hubbar y Theodora Kimball y en un principio se tradujo en la creación de una revista, paralela a la oficial de la ASLA, enfocada a temas urbanos. Pero, como cuenta Melanie Simo (2000), el impacto de mayores consecuencias no llegó hasta 1929, cuando el planeamiento urbano, que previamente había sido una asignatura dentro del curso de arquitectura del paisaje, se constituyó como un título independiente. Como hemos visto, dentro de la ASLA tuvo mucha importancia esta división, que obligó a entender la arquitectura del paisaje o bien como algo artístico, próximo al diseño del

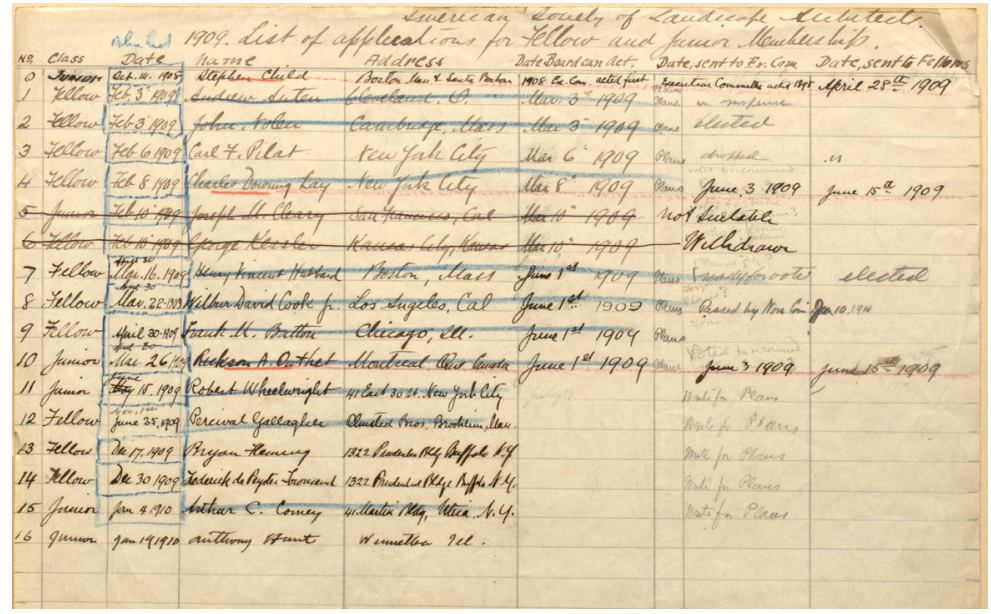

jardin, o como algo tecnificado, propio de la ciudad o la infraestructura. Las exigencias derivadas del New Deal no hicieron sino enfatizar esto.

En Harvard, la separación de asignaturas hizo que la titulación de la arquitectura del paisaje se enfocara casi únicamente al diseño del jardín. A partir de ese momento, primó la crítica estilística a los trabajos. Las referencias al jardín italiano e inglés fueron vistas como historicistas por Joseph Hudnut y, posteriormente, por Walter Gropius. El exdirector de la Bauhaus, a su llegada a Harvard ejerció una influencia decisiva en las nuevas generaciones de paisajistas como Garrett Eckbo y Dan Kiley, que vieron en el estilo moderno una vía de escape a lo que consideraban un tradicionalismo estilistico anquilosado. (Eckbo 1987)

De este modo, al mismo tiempo que en la ASLA se debatió entre si su profesión se orientaba a las bellas artes o a las ciencias
Figura 12. Listado de posibles nuevos miembros en el que se aprecia la alta cantidad de nombres tachados y la baja aceptación.

Figura 13. Anuncio en la revista Your Garden and Home (c. 1930).

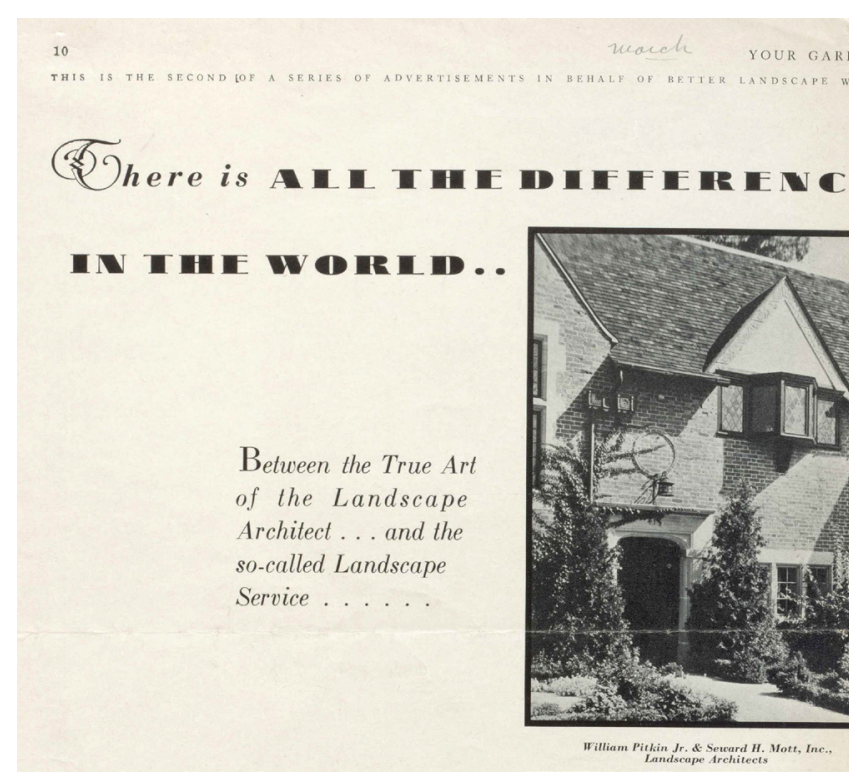


Figura 14. Mapas de la distribución geográfica de los miembros en 1936 y en 1944. Como se ve, la tendencia fue la emigración hacia el oeste.

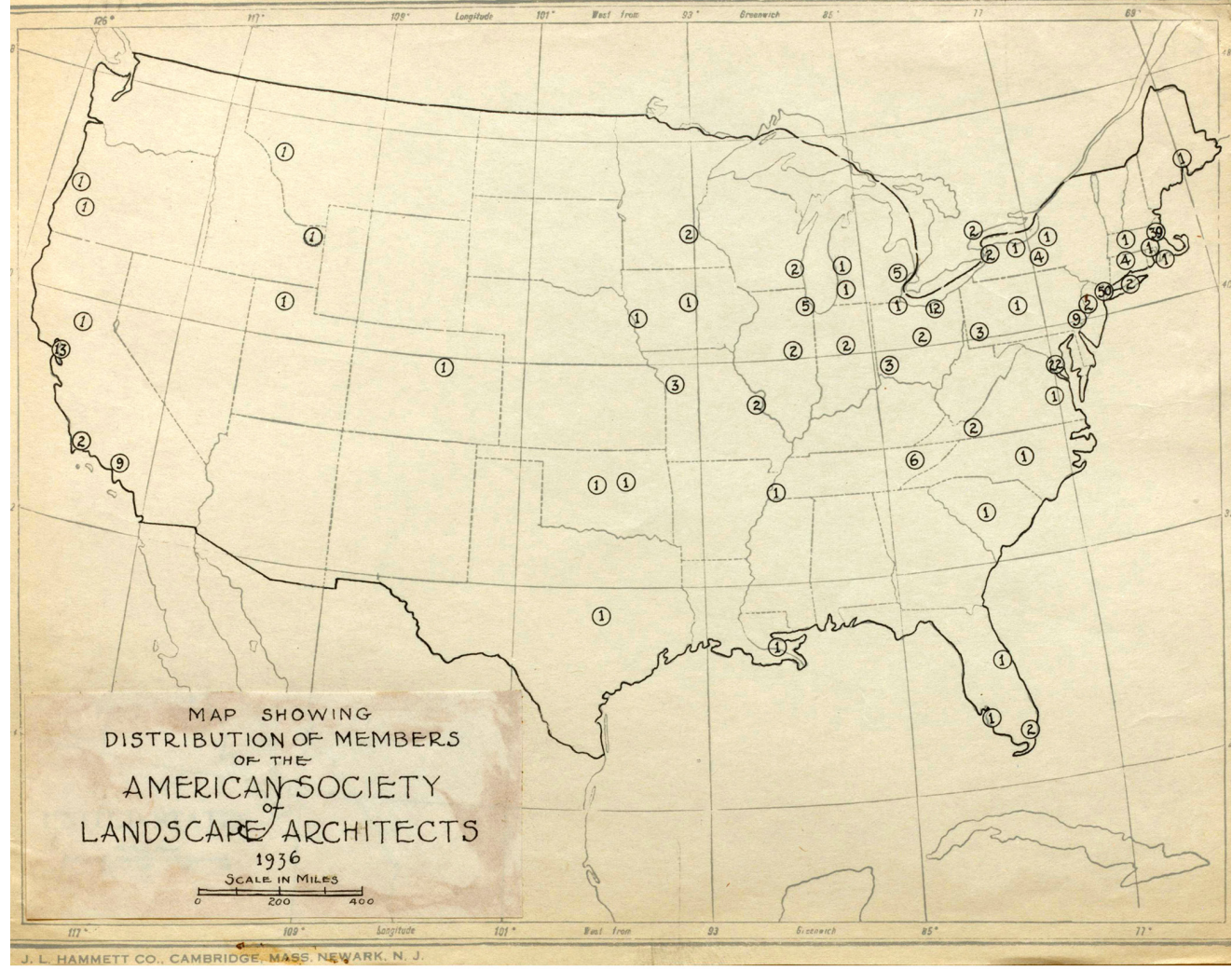

sociales, la enseñanza del paisaje se atomizó y sus principios estilisticos fueron cuestionados. Hemos visto aquí los problemas que la sociedad tuvo para hacer frente a esto. Algo que, junto a los pocos miembros con los que

contaba, afectó tanto a la profesión como a los paisajistas de aquella época, cuyos trabajos solo ahora están dejando de ser considerados como un momento de transición entre Olmsted Sr. y el movimiento moderno.

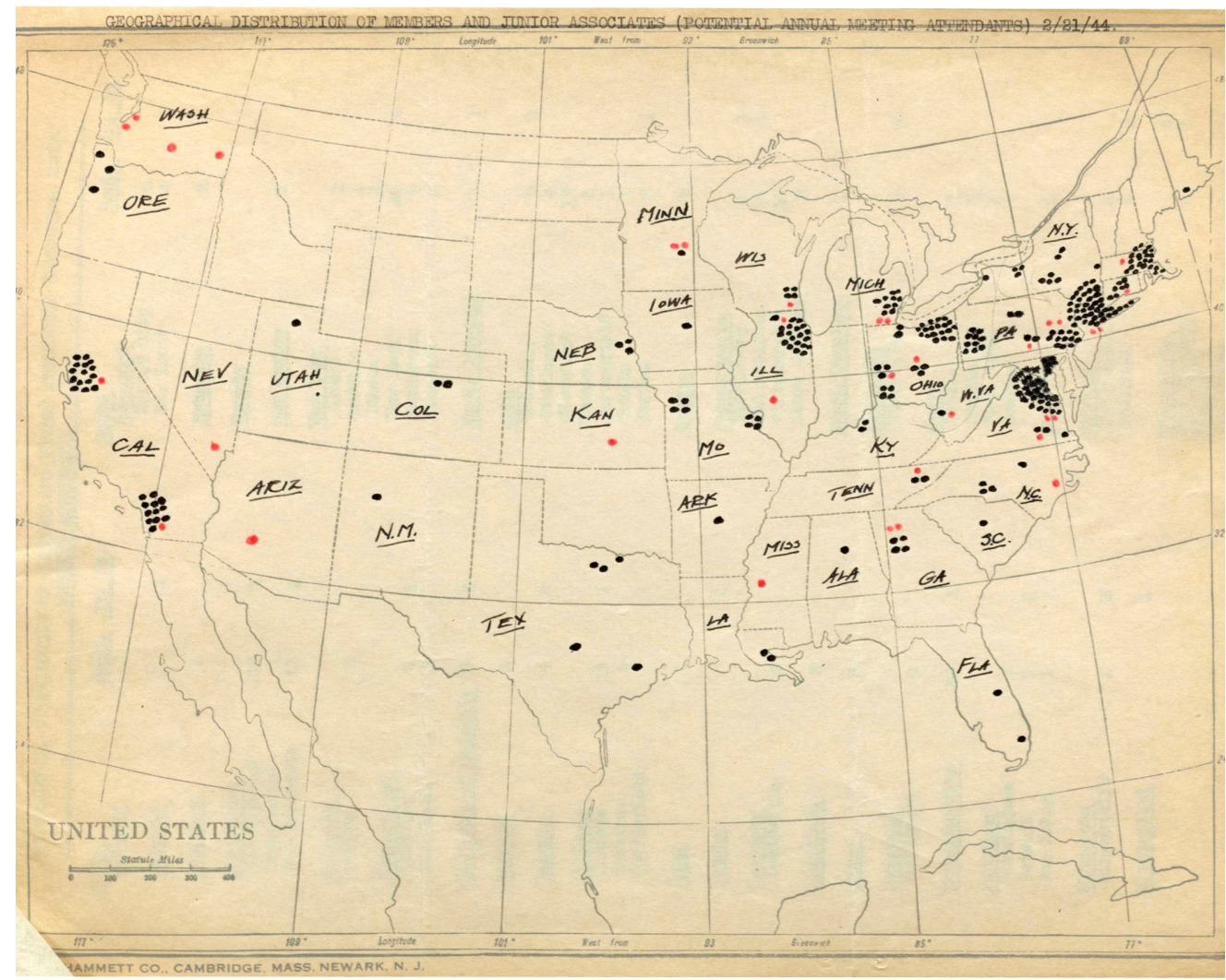




\section{Notas}

1 En concreto, los fondos estudiados han sido los "American Society of Landscape Architects Records", que van desde 1899 a 1966 y se alojan en la División de Manuscritos de la Biblioteca del Congreso de Estados Unidos (en el edificio John Madison). La colección consta de alrededor de 11.000 elementos, sobre todo cartas, memorias e informes que han sido consultados in situ por el autor y nunca publicados con anterioridad. Dada la extensión de las citas, y con la finalidad de facilitar la lectura general del texto, los fragmentos referidos han sido traducidos por el autor.

2 Se utiliza aquí impracticidad como traducción del término impractical usado por Olmsted.

3 La frase original, sell our birthright for a mess of pottage, es paráfrasis de una frase bíblica (Genesis 25:29-34). Como se aprecia en todo el texto, las referencias biblicas, místicas o mágicas son continuas en los escritos de la Sociedad. Aparecen citas directas de la Biblia, comparaciones de los miembros con los apóstoles o el mesias, e incluso, de los profesionales con la misma figura de Dios. Esto parece querer forzar el carácter elevado que se atribuía a la arquitectura del paisaje y a la ASLA, que llegó incluso a nombrar los Diez Mandamientos como una de las referencias fundamentales de sus estatutos.

4 Realmente John Charles era sobrino de Frederick Law pero, al morir su hermano, Olmsted desposó a su viuda y adoptó a sus hijos. A pesar de ello, si lo que cuenta Roper (op. cit.) es cierto, nunca tuvo a John Charles la misma consideración que a su primogénito.

5 La familia Eliot forma parte de la élite burguesa de Boston y, además de contar con varios miembros de renombre y un premio Nobel (el poeta T.S. Eliot), parecian tener cierta predilección por el nombre Charles. En el artículo se mencionan tres: Charles William Eliot (1834-1926), presidente de Harvard durante más de 40 años Charles Eliot (1859-1897), su hijo, reconocido paisajista que falleció a muy temprana edad, y Charles William Eliot II (1899-1993), nieto de primero y sobrino del segundo, también paisajista y urbanista reconocido. Este último es el que elaboró los bocetos para el memorial de los Olmsted.

6 Esta frase sintetiza una más larga que aparece en una carta de invitación que se envió a la ASLA para formar parte de una exposición conjunta en la Academia de Bellas Artes de Pennsylvania. La cita completa es: "La exposición comprenderá el campo de la Arquitectura en su sentido más amplio, e incluirá todas las artes aliadas de las que ella es madre".

7 Todos los subrayados que aparecen en las citas a lo largo del texto aparecen en el documento original.

8 En esa misma época es cuando escribe la biografía de Frederick Law Olmsted junto a Olms ted Jr.

9 Dado que el documento "VVAA (1895) Cartas a William H. Manning" se compone de la respuesta de varios autores, se marca aquí la página del documento seguido del nombre del autor de la carta.

10 La imagen de L'Enfant cambiará para la ASLA cuando llegue el momento de plantear un nuevo plan urbano para Washington DC. Entonces se le encumbró como un muy digno antecedente de la arquitectura del paisaje en América cuyos planes no habian sido correctamente llevados a cabo.

\section{Bibliografia}

ASLA, 1912. Transactions of the American Society of Landscape Architects 1899-1908. Harkisburg: Mt. Pleasant Pkbss. Disponible online: https://babel.hathitrust.org/cgi/pt?id=uva x000998003; view=1up;seq=9 (última consulta 22/04/2019).

ASLA, 1922a. Transactions of the American So ciety of Landscape Architects 1909-1921. Amsterdam, (N.Y.): The Recorder press. Disponible online: https://babel.hathitrust.org/cgi/ pt?id=mdp. 39015006949633 (última consulta 22/04/2019).

ASLA, 1922b. A. S. L. A. notes. Landscape Architecture (A quarterly), 13(1), 75-78.

ASLA, 1940. Policies. Landscape Architecture (a quaterly), 30, número completo.

Baird, Timothy y Szczygiel, Bon. 2006. "Sociology of Professions: The Evolution of Landscape Architecture in the United States". Landscape Review 12(1), 3-25.

Birnbaum, Charles A. y Crowder, Lisa E. (Eds.) 1993. Pioneers of American landscape design: an annotated bibliography. Washington D.C. U.S. Department of the Interior, National Park Service.

Brown, Robert D. y CORRY, Robert C. 2011. Evidence-based landscape architecture: The maturing of a profession. Landscape and Urban Planning 100(4), 327-329.

CHILD, Stephen. 1911. Landscape Architecture: a definition and resume of its past and present. Chicago: R.J. Haight.

CoRner, James. 2014. The Landscape Imagination: The Collected Essays of James Corner 19902010. New York: Princeton Architectural Press.

Disponzio, Joseph. 2001. From garden to landscape: Jean-Marie Morel and the transformation of garden design. AA Files, 44, 6-20.

Disponzio, Joseph. 2014. Landscape architecture: a brief account of origins. Studies in the History of Gardens \& Designed Landscapes, 34(3), 192200.

DümPelman, Sonja. 2014. What's in a word: on the politics of language in landscape architecture. Studies in the History of Gardens \& Designed Landscapes, 34(3), 207-225.

Eскво, Garrett. 1987. The Work of Garrett Eckbo: Landscape for a Living. Charlottesville: The University of Virginia.

Geoffrey, Jellicoe. 1961. A Table for Eight. En ed. CRowe, S. (ed.) Space for Living: Landscape Architecture and the Allied Arts and Professions. Amsterdam: Djambatan N.V., 13-21.

Kalfus, Melvin. 1981. Olmsted: A psychohistorical perspective. En BRUCE, K. (ed.) Art of the Olmsted 
Landscape. Nueva York: New York City Landmarks Preservation Commission,

Klaus, Susan L. 1997. All in the Family: The Olmsted Office and the Business of LA. Landscape Journal 16(1), 80-95.

NadeniceK, Daniel J. y Hastings, Catherine M. 2000. Environmental Rhetoric, Environmental Sophism: The Words and Work of Landscape Architecture. En Conan, M. (ed.) Environmentalism in Landscape Architecture. Washington D.C.: Dumbarton Oaks, 133-162.

NASAR, Jack L. y JoHnson, Elsa. 1990. The Personality of the Profession. Landscape Journal 9(2), 102-108.

Newton, Norman T. 1971. Design on the Land: The Development of Landscape Architecture. Cambridge: Balnak Press.

Olmsted, Frederick Law. 1871. Public parks and the enlargement of towns. Cambridge:American Social Science Association.

Olmsted, Frederick Law. 1882. The spoils of the park: with a few leaves from the deep-laden note-books of 'a wholly unpractical man'. Detroit?: s.n. Disponible online: http://hdl.handle. net/2027/hvd.32044046628129 (última consulta 22/04/2019).

Olmsted, Frederick Law [1886]. 1921. A letter relating to professional practice from F. L. Olmsted, Sr., to Charles Eliot, 8th Oct., 1886. Landscape Architecture (A quarterly), 11(julio), 189-190.

Olmsted, Frederick Law. 1888. Letter to the board of park commissioners in Rochester. En Olmsted Jr., F. L. y Kimball, T. 1922. Frederick Law Olmsted: landscape architect (1822-1903). Vol. 1: Early years and experiences. New York and London: G. P. Putnam's Sons.

Olmsted Jr., Frederick Law y Kimball, Theodora. 1922. Frederick Law Olmsted: landscape architect (1822-1903). Vol. 1: Early years and experiences. New York and London: G. P. Putnam's Sons.

Peterson, Jon A. 2003. The Birth of City Planning in the United States, 1840-1917. Baltimore: Johns Hopkins University Press.

Roper, Laura W. 1983. F.L.O.: A Biography of Frederick Law Olmsted. Baltimore: Johns Hopkins University Press.

Roulier, Scott. 2017. Shaping American Democracy: Landscapes and Urban Design. New York: Springer.

Scazzosi, Lionella. 2004. "Reading and assessing the landscape as cultural and historical heritage", Landscape Research 29(4): 335-355

SchuYLER, David. 1986. The New Urban Landscape: The Redefinition of City Form in Nineteenth-Cen tury America. Baltimore: Johns Hopkins University Press

ShURTLEFF, Flavel. 1914. The landscape architect in city planning. Landscape Architecture (A quarterly), 5(1), 143-147.

Simo, Melanie L. 1999. 100 Years of Landscape Architecture Some Patterns of a Century. Washington, D.C.: Spacemaker Press.

Simo, Melanie L. 2000. The Coalescing of Different Forces and Ideas: A History of Landscape Architecture at Harvard, 1900-1999. Cambridge: Harvard University Graduate School of Design.

SPIRN, Anne W. 1997. The authority of nature: conflict and confusion in landscape architecture. En
Wolschre-Bulmahn, J. (ed.) Nature and Ideology: Natural garden design in the twentieth century. Washington D.C.: Dumbarton Oaks, 249-261.

Sutton, Susane. 1971. Frederick Law Olmsted, 1822-1903: Introduction. En SutTon, S. (ed.) Civilizing American cities; a selection of Frederick Law Olmsted's writings on city landscapes. Cambridge: MIT Press.

Vernon, Noël D. 1987. Toward Defining the Profession: The Development of the Code of Ethics and the Standards of Professional Practice of the American Society of Landscape Architects, 18991927. Landscape Journal 6(1), 13-20.

Vitale, Ferrucio. 1905. Italian Gardens. En ASLA. 1912. Transactions of the American Society of Landscape Architects 1899-1908. Harkisburg: Mt. Pleasant Pkbss.

WALDHEIM, Charles. 2014. Introduction: landscape as architecture. Studies in the History of Gardens \& Designed Landscapes, 34(3), 187-191.

WALKER, 1908. The relations of the architect and the landscape architect. En ASLA, 1912. Transactions of the American Society of Landscape Architects 1899-1908. Harkisburg: Mt. Pleasant Pkbss.

Fondos consultados en la división de manuscritos de la Librería del Congreso de los EEUU. Colección: American Society of Landscape Architects records, 1899-1966.

ASLA, 1919. Summary of minutes of the 20th Annual Meeting and dinner of the A.S.L.A. $(24 \mathrm{de}$ enero). Caja 1: General correspondence, 19061920/ 1919

ASLA, 1926. Policies, with commentaries. Caja 12/ Committee on Policies, 1930-1951.

Borie, C. y Trask, J. 1906. Propuesta de exhibición conjunta en la Academia ed las Artes de Pennsilvania. Caja 1: General correspondence, 19061920/ 1906-1912.

Chambers, Walter L. 1943. Memorandum to the Board of Trustees (13 de febrero). Caja 12/ Committee on City, Regional and National Planning, 1917-1959.

Child, Stephen. 1916. Report of Committee on Professional Practice and Ethics (4 de enero). Caja 1: General correspondence, 1906-1920/ 1916.

Comité Ejecutivo. 1914. Policies proposed by the Executive Committee for adoption by the A.S.L.A (5 de septiembre). Caja 12/ Committee on Policies, 1914-1929.

Comité Ejecutivo. 1916. Memorandum for Mr. Brinckerhoff (14 de febrero). Caja 12/ Committee on Policies, 1914-1929.

Eliot, Charles W. 1923. Carta a Bremer W. Pond (17 de diciembre). Caja 2: General correspondence, 1921-1933/ 1923.

Eliot, Charles W. 1924. Carta a James S. Pray (13 de febrero). Caja 2: General correspondence, 1921-1933/ 1924.

EXAmining BOARD. 1910. Report. Caja 1: General correspondence, 1906-1920/ 1906-1912.

GreEnLEAF, James L. 1911. Anual report of the Examining Board (10 de enero). Caja 7/ Examining Board, 1910-1925.

GREenLEAF, James L. 1924. Opening remarks in the 25th anual meeting of the A.S.L.A. (14 de enero). Caja 2: General correspondence, 1921-1933/ 1924. 
Greenleaf, James L. 1925. Report of the President (31 de diciembre). Caja 2: General correspondence, 1921-1933/ 1925.

Hall, George D. (c. 1933. The practice of landscape architecture as a function of governmment: Federal, State and Local. Caja 12/ Committee on Practice of Landscape Architecture by Governmental Agencies, 1931-1936.

Hare, Herbert. 1943. Carta a Bradford Williams (8 de junio). Caja 12/ Committee on City, Regional and National Planning, 1917-1959.

HubBard, Henry V. 1914a. Carta a Alling S. DeForest (14 de septiembre). Caja 1: General correspondence, 1906-1920/ 1914.

Hubbard, Henry V. 1914b. Carta a Alling S. DeForest (17 de septiembre). Caja 12/ Committee on Policies, 1914-1929.

HubBard, Henry V. 1933. Carta a los miembros de la Junta Directiva (20 de junio). Caja 2: General correspondence, 1921-1933/ 1933.

Junta Directiva. 1917. Carta a Harold A. Caparn (11 de abril). Caja 12/ Committee on Policies, 19141929.

Manning, Warren H. 1911. The standing of our profession in its relation to the public and to other professions (21 de marzo). Caja 1: General correspondence, 1906-1920/ 1906-1912.

Manning, Warren H. 1915. Report of the President (12 de enero). Caja 1: General correspondence, 1906-1920/ 1915

Olmsted Jr., Frederick Law. 1905. Carta a Downing Vaux (16 de agosto). Caja 1: General correspondence, 1906-1920/ 1906-1912.

Olmsted Jr., Frederick Law. 1917a. Carta a los miem bros de la National Conference on City Planning (12 de mayo). Caja 1: General correspondence, 1906-1920/ 1917.

Olmsted Jr., Frederick Law. 1917b. Resolution adopted by the ninth National Conference on City Planning at Kansas City, Missouri (9 de mayo). Caja 1: General correspondence, 1906-1920/ 1917.

Pond, Bremer W. 1931. Report of the Secretary. Caja 2: General correspondence, 1921-1933/ 1931.

PRAY, James S. 1915. Report of the Secretary (12 de enero). Caja 1: General correspondence, 19061920/ 1915.

PRAY, James S. 1917. President's report (9 de enero) Caja 1: General correspondence, 1906-1920/ 1917.

Pray, James S. 1919. President's report (7 de marzo). Caja 1: General correspondence, 1906-1920/ 1919.

Pray, James S. 1924. Carta a Charles W. Eliot (14 de febrero). Caja 2: General correspondence, 19211933/ 1924.

Schermerhorn, Richard. 1924. Carta a James L. Greenleaf (19 de marzo). Caja 2: General correspondence, 1921-1933/ 1924.

Stevenson, Markley. 1934. Carta a Bradford Williams (26 de septiembre). Caja 12/ Committee on Practice of Landscape Architecture by Governmental Agencies, 1931-1936

TAYloR, A.D. 1943. Carta a Herbert Hare (12 de junio). Caja 12/ Committee on City, Regional and National Planning, 1917-1959.

Vitale, Ferrucio. 1927. Carta al secretario de la ASLA (11 de noviembre). Caja 3/ Committee on Allied Arts, 1927-1935.
VVAA. 1895. Cartas a William H. Manning, varias fechas. Caja 1: General correspondence, 1906 1920/ 1906-1912.

VVAA. 1911. Cartas a William H. Manning (21 de marzo). Caja 1: General correspondence, 1906 1920/ 1906-1912.

Williams, Bradford. 1958. Carta a Merel S. Sager (3 de marzo). Caja 9/ Committee on Olmsted Memorial, 1923-1960.
Fecha final recepción artículos: 25/04/2019

Fecha aceptación: 18/06/2019

Artículo sometido a revisión por dos revisores independientes por el método doble ciego. 